\title{
The Effects of Usury Laws: Evidence from the Online Loan
}

\author{
Market* \\ Oren Rigbi ${ }^{\dagger}$ \\ Ben-Gurion University
}

June 2010

\begin{abstract}
Usury laws cap the interest rates that lenders can charge. Using data from Prosper.com (an online lending marketplace), I show how interest rate caps affect 1) the probability that a loan is funded 2) the amount a borrower requests 3) the interest rate at which a loan is funded, and 4) loan repayments. The key to my empirical strategy is that there was initially substantial variability in states' interest rate caps, in which Prosper borrowers from different states faced different caps ranging from 6 to $36 \%$. A behind-the-scenes change in loan origination suddenly increased the cap to $36 \%$ in all but one state. This change, which was not pre-announced, created "treatment" states whose caps rose and few control states whose caps remained unchanged. I find that higher interest rate caps increase the probability that a loan be funded, especially if its borrower is risky and had been previously
\end{abstract}

${ }^{*}$ This is a revised version of chapter 1 of my Stanford 2009 dissertation. I am particularly indebted to my advisors Liran Einav, Caroline Hoxby and Ran Abramitzky for their encouragement and continuous support. I also benefited from discussions with Itai Ater, Ginger Jin, Jakub Kastl, Jon Levin, Yotam Margalit, Christopher Peterson, Monika Piazzesi, Frank Wolak, Seema Jayachandran, Yaniv Yedid-Levi, conference participants at the annual meetings of the American Law and Economics Association, the European Association for Research in Industrial Economics and the International Industrial Organization Conference as well as seminar participants at various universities. Neale Mahoney kindly provided individual exemption data. I gratefully acknowledge financial support from the Stanford Olin Law and Economics Program, the Shultz Graduate Student Fellowship, the SIEPR Fellowship, and the European Commission Marie Curie International Re-integration Grant.

${ }^{\dagger}$ Mailing Address: Department of Economics, Ben-Gurion University of the Negev. P.O.B 653, Beer-Sheva 84105, Israel. Email: origbi@bgu.ac.il. 
just "outside the money." I do not find that borrowers change the loan amounts they request or that their probability of default rises. The interest rate paid, however, rises slightly probably because online lending is imperfectly integrated with credit markets. 


\section{Introduction}

Legislated caps on interest rates, known as usury laws, are one of the oldest forms of market regulation. Usury laws have inspired great debate, as do other forms of government intervention in financial markets. Opponents argue that interest rate caps exclude higher risk borrowers from obtaining credit or developing a credit history. Proponents, on the other hand, argue that caps reduce the interest rates paid by a given borrower because lenders cannot exercise their market power. They also argue that interest rate caps prevent naive borrowers from agreeing to loan terms on which they will eventually be forced to default. This paper empirically examines each of these arguments by exploiting a sudden and unforeseen shift in the interest rate caps which affected online borrowers. The paper's main advantage is clean identification of the effects of usury laws, facilitated by an exogenous change that allows me to rule out confounding phenomena. In addition, I not only use very detailed data, but I also observe virtually all the information observed by lenders. This allows me to eliminate selection problems that have plagued previous work on usury laws.

Economic theory suggests that interest rate caps may affect credit markets through various channels. First, higher caps make lending to higher risk borrowers profitable. That is, higher caps may result in credit being extended to borrowers who were previously denied credit. Second, because the riskiness of a loan depends on its size and not just on the identity of the borrower, higher caps may cause a given borrower to request a larger loan. Third, higher caps may increase the probability that borrowers default on loans, particularly if the caps were "protecting naive borrowers from themselves"-that is, preventing borrowers from agreeing to loan terms that they could not manage financially. Finally, theory suggests several routes by which interest rate caps could reduce the price paid for any given loan. If lenders have market power, then usury laws could decrease the interest rates charged by shifting the market toward the price that would be obtained in the absence of market power. Even if lenders have no market power, they may be in inelastic supply of credit. If they are, then the price of credit will rise with the cap simply because a greater number of borrowers who request loans under a higher cap will drive up demand for credit.

I use new data from Prosper.com, the largest online person-to-person loan marketplace in the U.S. I observe full details on the universe of Prosper's loan requests, loan originations, 
and loan repayments. Prosper's recent history provides an informative "natural experiment." Prior to April 15, 2008, a Prosper borrower's interest rate cap was governed by his state's usury law. State's caps varied between 6 and 36\%. On April 15, 2008, however, a formal change in Prosper's loan origination suddenly changed its borrowers' interest rate cap to $36 \%$ in all states but one. In other words, borrowers in most states faced sudden increases in their interest rate cap, and borrowers in a few states faced no change. (In addition to the one state whose low cap did not change in April 2008, there were a few states that already had caps of $36 \%$.)

Given the experiment just described, the empirical strategy I use to study the effects of usury laws is differences-in-differences. That is, I compare several outcome variables across time (before and after April 15, 2008) and across states (treated and control states). The strategy is richer than one may think at first glance because the states' initial conditions varied. Some states' borrowers saw their cap rise by only $11 \%$, while others saw it rise by as much as $30 \%$. I exploit this variation to estimate non-linear effects of a percentage point change in the interest rate cap. Moreover, since we expect the effect of an interest rate cap to depend on a borrower's riskiness, I estimate fully heterogeneous effects - specifically, I allow the effect to vary with a borrower's credit grade.

I empirically examine each of the theoretical predictions described above. My first cut at the data is a very simple comparison of outcomes before and after April 2008. For instance, I investigate whether a high risk borrower's loan request is more likely to be funded after his rate cap rises to $36 \%$. Following this simple but fairly revealing analysis, I exploit the full richness of the data in order to test the theoretical predictions while accounting for endogeneity and selection (see below). In particular, I analyze whether a given loan is more likely to be funded if its borrower was previously risky enough to be restricted by his state's interest rate cap. Interestingly, I find that the largest increase in funding probability is experienced by borrowers who were previously just "outside the money" in their state. To address the concern that the amount requested by a borrower might be endogenous to the interest rate cap, I investigate whether borrowers request larger loans following an increase in the cap. My findings show that they do not. I also find that, for a given type of borrower and loan amount, loan repayment patterns such as default do not change following an increase in interest rate caps. Finally, I 
analyze whether a given borrower pays a higher price for credit when his interest rate cap rises, and find zero to small increases (no more than 130 basis points) in interest rates paid.

I mention two reasons why interest rates might rise - in this case, very slightly - with interest rate caps. I look for direct evidence of the second explanation: an inelastic supply of credit. For instance, I investigate whether interest rates go up for low risk borrowers in states that initially had $36 \%$ caps-borrowers who would be unaffected by the April 2008 change if the supply of credit were perfectly elastic. My results suggest that the supply of credit on Prosper is at least slightly inelastic. Furthermore, an explanation to an increase in the interest rates that is based on lender's market power is implausible given the low concentration levels of lenders at Prosper. Since Prosper's borrowers do not constitute a large share of total U.S. borrowing, these findings suggest that Prosper is imperfectly integrated into credit markets. This is not altogether surprising because it operates online and most of its lenders are individual investors rather than institutional investors.

Selection problems have plagued previous researchers of usury laws. Selection might be a problem because an individual's decision to apply for a loan depends on his expectation that the loan will be funded. Moreover, if the probability that a loan is funded depends on the maximum interest rate the borrower is allowed to pay, then the composition of individuals applying for loans changes when the cap changes. Estimates of the effects of interest rate caps are, therefore, often confounded with the changing composition of borrowers (selection). I am able to control much better for selection than previous authors because of a unique feature of Prosper's data. Because the marketplace is online and virtually everything about a loan that appears online is recorded in the data, I observe essentially all the information that potential lenders observe. (The only information I do not observe is information that might have been exchanged in Prosper-related chatrooms.) Thus, selection of borrowers on unobservables is at most a very minor issue. So as long as I control sufficiently flexibly for observable characteristics of borrowers and their loan requests, selection should not be a problem. This is in contrast to previous studies in which loans were typically originated through in-person interviews of applicants, in which loan officers could observe a great deal of information that the econometrician missed.

The richness of the Prosper data allow me to fully exercise the power of a differences- 
in-differences strategy. I control for time effects that are constant across states, state effects that are constant across time, credit grade effects, state-by-credit grade effects, time-by-credit grade effects, and so on through all the "two-way" effects.

The remainder of the paper is organized as follows. Section 2 provides background information on usury laws, reviews the related literature and introduces Prosper's natural experiment. Section 3 describes the data. I motivate and describe my empirical strategy in section 4. Basic evidence from a simple first cut of the data is presented in Section 5 . Section 6 presents regression-based analysis in which I account for selection and endogeneity. I examine the robustness of the findings in section 7 . In section 8 , I discuss the findings and conclude.

\section{Background}

\subsection{The Origins of Usury Laws and Their Evolution in the American Legal System ${ }^{1}$}

The earliest references to usury laws are in Hammurabi's code of 1800 B.C. in ancient Mesopotamia and the ban on interest rates which shows up three times in the five books of Moses. Specifically, the issue also comes up again in Exodus and the book of Luke in which strong limitations on the rates that lenders can charge are advocated 2 In the modern era, usury laws are one of the only topics for which Adam Smith was skeptical of adopting a "laissez-faire" solution. In a famous exchange with the philosopher Jeremy Bentham, Smith refused to rule out the necessity of legal ceilings on interest rates 3 Usury laws made their way into the American legal system through the American colonies, which adopted existing English usury statutes. The proliferation of loan-sharking in the 19th century stimulated the evolution of lending institutions such as credit unions that were intended to be non-predatory. Credit unions are often based on a common employer, church, or social organization. However, such institutions have left many borrowers without credit and policy makers sought a way to make consumer

\footnotetext{
${ }^{1}$ The description of the evolution of usury laws in the American legal system is based on Renuart and Keest (2005), section 3.2 .

${ }^{2}$ For historical reviews of usury laws see Frierson (1969), Homer and Sylla (2005), Shanks (1967) and Glaeser and Scheinkman (1998).

${ }^{3}$ The letters written by Bentham were published in Bentham (1818). For a detailed description of the correspondence as well as the thoughts of early philosophers' on usury see Persky (2007).
} 
lending profitable without being predatory

The Uniform Small Loan Law, enacted in 1916, was intended to address the too restrictive interest rate caps. The law created a class of lenders authorized to charge rates significantly in excess of the general usury caps in return for the lenders' agreement to be regulated ${ }^{5}$ Each usury law was aimed at a particular type of creditor, a particular type of transaction, or some combination of the two ${ }^{6}$ However, as the number of special credit laws in each state became unwieldy, attempts were made to consolidate the credit laws into simplified statutes ${ }^{7}$

During the 1970s, inflation drove commercial market rates above $20 \%$, rates significantly higher than most usury ceilings. Fearing that consumer credit would dry up, the federal government preempted many states' usury limitations, subject to the proviso that a state could opt out of the federal preemption if it enacted legislation proclaiming that the state did not want the federal preemption to apply to it. The federal action thus forced states to reconsider their often complex sets of general and special statutes. In the 1980s, states followed one of several paths for interest rate caps regulation. Some states repealed their general usury caps entirely, allowing parties who were not regulated by special usury laws to contract on any agreed rate. Other states modified their general usury laws so that caps would fluctuate with a published market interest rate. Most states, however, simply raised their interest caps to a point that did not bind traditional lenders access to credit. In the last decade, most legal activity can be described as a trench warfare between state and city-level attempts to curb what they believe is predatory lending and federal attempts to preempt this activity. The rapid growth of the payday loan industry in the past 15 years is an example for how usury laws are constantly challenged or legally evaded. Written with short terms and for occasional use, payday loans are exempted from many state and local usury laws. Recently, nonetheless, usury laws have been extended to payday loans by either banning them or by reforming them

\footnotetext{
${ }^{4}$ Benmelech and Moskowitz (2010) provide evidence that the imposition of usury laws in the 19th century America was driven by private groups that used regulation to extract rents from other groups.

${ }^{5}$ For example, the regulation imposed on consumer credit sales was mainly through restrictions on finance charges.

${ }^{6}$ The types of creditors that were distinguished by the law are depository lenders such as banks and credit unions, and non-depository lenders such as licensed lenders or retail sellers. The types of credit that are discerned by the law are loan vs. credit sales, open end vs. closed-end credit (e.g. credit for an auto sale transaction vs. bank credit card) and secured vs. unsecured credit. See Pridgen (2003) for a practitioner guide that exemplifies the variety of usury laws.

${ }^{7}$ The most recognized attempt to consolidate usury laws is the Uniform Consumer Credit Code originally approved in 1968. Ten states have adopted forms of it, whereas other states have various portions of it.
} 
to reduce serial borrowing ${ }^{8}$

\subsection{The Debate on Usury Laws}

The debate over government constraints on the maximum price of credit has attracted the attention of philosophers, legal scholars and economists. Most arguments in favor of usury laws are focused on consumer protection. One argument is that usury laws limit the market power of lenders. This argument is often expressed with the claim that usury laws provide borrowers credit at a "fair" price $9^{9}$ Another argument is paternalistic: usury laws prevent naive borrowers from entering into loan contracts that reduce their utility under rational expectations, even though they did not expect utility reduction themselves 10

Opponents of usury laws argue that the reason some borrowers face high rates is not market power but one of risk: lenders will not lend if it is unprofitable. In other words, it is argued that interest rate caps inefficiently exclude some borrowers from getting credit. Being deprived of credit not only has immediate effects on the borrower, it also affects his ability to build a credit history, which is essential for being able to borrow at lower rates in the future. Opponents also argue that borrowers who are denied credit from legal lenders resort to illegal loan sharks or other dubious means of obtaining liquidity. These means may have far worse consequences than a conventional loan with an interest rate that a consumer advocate would describe as "high."11

\subsection{Previous Empirical Evidence}

The longstanding debate on usury laws and the substantial variability in interest rate caps across states have generated a large body of research on the effects of usury laws. Most of the literature dates from the 1970s and early 1980s when, partly because of inflation, there was significant popular dissatisfaction with usury laws. In an early work, Blitz and Long (1965) apply economic theory to usury regulation and generate testable predictions for its effects. Building on their analysis, Goudzwaard (1968) and Shay (1970) use aggregate data on 32 states

\footnotetext{
${ }^{8}$ See Stegman (2007).

${ }^{9}$ E.g. Brown (1992). This argument was supported by the view that when lenders have market power, usury laws redress the unequal bargaining power between borrowers and lenders; see for example Durkin (1992), Hayeck (1996) and Rougeau (1996).

${ }^{10}$ See Wallace (1976).

${ }^{11}$ See Finchler (1993), Oeltjen (1975) and Waterman (1979).
} 
to study the correlation between interest rate caps and the risk accepted by consumer finance companies. In 1971, the National Commission on Consumer Finance collected data from a large national lender. Greer $((1974),(1975))$ used that data to study the effect of caps on the risk undertaken by lenders, lending activity, and rejection rates. Greer focuses on how the caps affect aggregate indicators, and not individual loan requests. Villegas((1982),(1989)) employs individual-level data from the Consumer Expenditure Survey of 1972 and 1983 to examine the correlations between interest rate caps, price of credit, and access to credit. Villegas accounts for truncation in the dependent variable using a Tobit model, which is an improvement over previous studies. Nevertheless, his data do not contain sufficient variation to allow him to separate the effect of the cap from the potentially confounding effect of the risk associated with the locality of the borrower. In addition, his data are insufficiently rich to account for selection of borrowers into the sample. Alessie, Hochguertel, and Weber (2005) employ a rich individual-level data set covering loan requests received by a large Italian provider of consumer credit from 1995 through 1999 to analyze the imposition of a single interest rate cap. Compared to my study, they cannot control very well for time effects (since the cap changes identically for all borrowers at a point in time) and cannot adequately address selection of borrowers (since they have only some of the information lenders observe).

Results from the previous literature nearly always indicate that lower rate caps reduce the amount of credit given. Effects on other outcomes, such as the amount requested, the rate at which a loan is funded and loan repayment are more ambivalent or not addressed.

\subsection{Prosper.com}

Prosper is an online platform for lenders and borrowers to interact and originate fixed rate, unsecured consumer loans of $\$ 1,000$ to $\$ 25,000$. Recently Prosper has introduced a secondary market for loans originated by other financial institutions (e.g., auto lenders and small business lenders) ${ }^{12}$ Loans are originated through a uniform price auction. In order to borrow money a borrower posts a listing in which he indicates the amount requested and the maximum

\footnotetext{
${ }^{12}$ Prosper operated solely as an online person-to-person marketplace till October 15,2008 . It then started a registration process with the SEC so that it could introduce a secondary market to trade loans between individual lenders. As a result, new loans were not able to be issued through the web site. On April 28, 2009 Prosper re-launched its web site with two operating platforms. The first is the original person-to-person loan marketplace, the second is a marketplace for financial lenders to sell loans that they have recently issued.
} 
interest rate he is willing to pay subject to usury limitations. Prosper adds objective financial information to the listing that it gathers from credit bureaus including the borrower's credit grade letter, delinquencies, public records, and credit line history. In addition, the borrower is asked to indicate his intended use of the loan and to describe his financial situation. Borrowers can also post a photograph.

Lenders may bid on portions of the listing. A lender's bid consists of an amount that is greater than $\$ 50$ and the minimum interest rate the lender agrees to be paid for the loan. Lenders can browse listings manually or use pre-defined or customized portfolio plans. A portfolio plan is an automatic bidding tool that bids on listings that match a specific bidding criteria ${ }^{13}$ A typical bidding criteria is a function of the verified financial information from credit-reporting agencies that is provided by Prosper. A loan is originated only if it is fully funded by lenders. If prospective lenders' bids exceed the size of the loan request, then the bids with the lowest interest rates win, and the interest rate paid by the borrower is the highest interest rate among the winning bids. Loans are fully amortized in monthly payments over three years. Borrowers who are late face a penalty. A loan that is more than one month late is turned over to a collection agency. Once a loan is more than four months late it is considered default and is sold to a debt buyer. If a borrower's loan is sold to a debt buyer, he is suspended from Prosper and his credit score is penalized substantially.

When Prosper began, it was formally the finance lender to issue loans, thus Prosper had comply with each state's small loan usury laws 14 However, since April 15, 2008, Prosper has begun to collaborate with a national bank that took over the formal role as the issuing finance lender. This "back office" change is invisible to Prosper's lenders and borrowers. Nonetheless, the collaboration allows Prosper to take advantage of a 1978 Supreme Court decision, Marquette National Bank of Minneapolis v. First Omaha Service Corp., that permits national banks to export their lender status from their home state to other states, thereby preempting the usury laws of the borrower's home state. Practically, the collaboration allowed

\footnotetext{
${ }^{13}$ The use of an automatic bidding engine was introduced into the Prosper web site on October 30, 2007. The bidding engine original version allowed lenders to choose one of several pre-defined portfolio plans. The bidding engine was upgraded on February 23, 2008 to allow lenders to define their own plans. Prosper declines to provide the penetration rate of portfolio plans. Yet, anecdotal evidence suggests that more than $50 \%$ of the bids are generated through automatic engines.

${ }^{14}$ For a full description of Prosper's regulatory status see Prosper's S1 Form at http : //www.sec.gov/Archives/edgar/data/1416265/000110465907078072/a07 - 27421_1s1.htm.
} 
Prosper to increase the interest rate cap to $36 \%$ regardless of the borrower's state of residence. It should be emphasized that Prosper did not advertise the collaboration in advance. Prosper simply informed its borrowers and lenders in an email and updated its blog with a relevant post 15

Despite Prosper's short history, it has already received scholarly attention. Freedman and Jin (2008) examine the firm's conduct in an in-depth investigation of the business model employed by Prosper. They study the evolution of the marketplace and the effects of its user interface. They also predict how the online marketplace will evolve as an alternative to traditional consumer credit markets. Herzenstein, Andrews, Dholakia, and Lyandres (2008) suggest that lenders at Prosper exhibit less discriminatory practices than those documented in US financial institutions. Pope and Sydnor (2010) and Ravina (2008) focus on the photographs Prosper borrowers post with their listings to question whether lenders discriminate on the basis of race, gender, or physical attractiveness. They find evidence of discrimination against racial minorities, against the overweight, and in favor of women, especially those whose appearance is rated above average.

\section{Data}

The data I use include information on listings, loans, loan repayments and marketplace participants. Most importantly, almost all the information that is presented in the web site and that can be used by participants is available ${ }^{16}$ When a borrower or a lender registers with the web site, Prosper verifies his identity using his social security number and bank account information. It then obtains his credit reports from the credit bureaus. The data available on each listing includes the verified financial information that Prosper obtains and some nonverified information that the borrower supplies. The borrower must indicate the amount he is requesting and the maximum interest rate he is willing to pay. This rate must be below the rate

\footnotetext{
${ }^{15}$ See $h t t p: / /$ blog.prosper.com/2008/04/15/site - update - \%e $2 \% 80 \% 93$ - april - 15 - 2008/ for the post. Prosper did not release a press release as at that time it was already available nationwide.

${ }^{16}$ Questions and answers between lenders and borrowers are the only pieces of information that are included in the listing's web page and that are not available. A borrower can choose to post the question and his answer in the listing's web page. An additional source of information that was easily accessible to participants is a users forum that was integrated into the web site until November 2007. The users forum was created to facilitate information and experience sharing between borrowers and lenders. Since then, the content of the forum was deleted and the permission to upload new postings was severely restricted. Discussions from the old forum are not available. Since the data I use starts at the end of October 2007, the deletion of the forums is not a concern.
} 
cap that is legal, given his state of residence. The verified information includes the borrower's credit grade letter (based on his credit score), past and current delinquencies, past and current negative public records, credit lines, and state of residence ${ }^{17}$ The unverified information includes the borrower's purpose for the loan, employment status, income, loan narrative, and photograph (if he wishes to post one) ${ }^{18} \mathrm{I}$ also use the interest rate the borrower agrees to pay, the interest rate cap that applies to his loan, and his repayments by month. While most states have a fixed cap, others let their cap move with the federal funds rate, and a few condition the cap on the amount or purpose of the loan ${ }^{19}$ In order to eliminate selection on the observables, I incorporate all verified information together with the self-reported information 20 Not only do I use all of the verified variables and borrower reported variables, but I include indicators for words and phrases that commonly appear in borrowers' statements about the purpose for their loan.

During its start-up period, Prosper made several changes to its user interface and the information provided in each listing's web page. Freedman and Jin (2008) document that these changes generated better screening of high-risk borrowers. In order to avoid the period of major changes, I focus my analysis on the period that begins on October 30, 2007 and ends on September 30, 2008 ${ }^{21}$ The cap increase on April 15, 2008 which is the event I exploit nicely centered in this period.

Figure 1 graphs the numbers of listings and loans, by month, originated at Prosper. For ease of presentation, I aggregate the credit grades (AA, A, B, C, D, E, HR) into three groups: super prime, prime, and sub prime ${ }^{22}$ The vertical line marks April 15, 2008. The

\footnotetext{
${ }^{17}$ See the Appendix for a detailed description of the variables included in the analysis.

${ }^{18}$ Upon loan origination, Prosper verifies the correctness of some of the non-verified information for a small fraction of the borrowers.

${ }^{19}$ For example, the interest rate restriction in California is $19.2 \%$ for loans up to $\$ 2550$, and $36 \%$ for loans in the range $\$ 2550-\$ 25000$. In Texas there is a limitation of $18 \%$ on business loans and $10 \%$ on loans intended for other purposes. In Arkansas the interest rate cap set at $6 \%$ higher than the federal funds rate.

${ }^{20}$ The proliferation of automatic bidding tools that are less compatible with the borrowers' narrative or with the photo posted by borrowers, suggests that they are not that crucial for the analysis. Yet, I incorporate them into the analysis.

${ }^{21}$ Repayment data cover repayments paid until April 2009. I use information about the first nine monthly repayments. Thus, only loans that were originated until the end of June 2008 are included in the repayment analysis.

${ }^{22}$ Prosper assigns each potential borrower to one of seven credit grade letters. The borrower's credit grade letter is based on the credit score provided by the credit bureau. Each credit grade letter corresponds to a 40 points credit score interval. Credit grade AA corresponds to a credit score greater than 760 . Credit grade A corresponds to credit score in the range 720-759. The remaining credit grades are - B, C, D, E, and HR. The corresponding credit score intervals are - 680-719, 640-679, 600-639, 560-599 and 520-559. It should be noted
} 
monthly number of super prime and prime listings increase moderately while the number of sub prime listings fluctuate. The number of loans rises in 2008 until the April 15 change and slightly decreases afterwards for all the groups of borrowers.

Figure 2 presents the funding probability, defined as the ratio between the number of loans and the number of listings. The funding probability exhibits an overall tendency to decrease for low-risk borrowers and to increase for high-risk borrowers. Figure 3 presents the average amount requested by borrowers in listings and loans. It shows a modest decrease over time for all credit score classes. Figure 4 shows that loans APR increased over time, especially for high-risk borrowers. Finally, Figure 5 presents the average value of four variables used to analyze repayments. ${ }^{23}$ It demonstrates that lower credit score borrowers exhibit a higher tendency to fail to repay their debt, and that loans originated after the change exhibit poorer repayment performance.

In Table 1, I present descriptive statistics for all the verifiable information on Prosper. Each variable is shown for the three credit score groups and the full sample of borrowers. Unsurprisingly, most of the financial indicators are significantly worse for sub prime borrowers. These borrowers exhibit worse repayment patterns across all repayment variables considered. In addition, the credit line variables suggest that borrowers with lower credit scores are more credit constrained: they have fewer credit lines, lower revolving credit balances, and higher utilization of their credit lines.

In Table 2, I present descriptive statistics for all the variables provided by the borrowers. Since all these variables are indicators, I report only their means. Approximately $40 \%$ of potential borrowers state that they plan to use the loan for debt consolidation. Borrowers in lower credit score groups have lower reported income and are less likely to be fully employed.

\footnotetext{
that following the web site re-launch Prosper changed this categorization.

${ }^{23}$ Data on loan repayments include the first 18 payments after loan origination. I consider four variables that summarize loan repayment. The first is a default variable indicating if a borrower is more than four months late. The second is the number of late payments which is censored from above at 4 , and takes the values $0,1, \ldots, 4$. Default loans are assigned the value 4 . The third is indicates if all first 18 payments are paid. The fourth variable indicates if the $18^{t h}$ payment is paid.
} 


\section{Empirical Strategy}

The empirical strategy taken in this research exploits the exogenous shock that occurred on April 15, 2008 in order to identify the treatment effects of a change in the maximum allowed interest rate. At the core of the empirical strategy is a comparison of the outcomes of two similar borrowers that face different interest rate caps due to posting their loan requests before versus after the change. This empirical strategy can be labeled as differences-in-differences; An exogenous shock to the maximum allowed interest rate in some states generates differences across treated and non-treated states. An additional difference in the time dimension is created by the point in time in which the shock occurred.

\subsection{The Basic Estimation Strategy}

The April 15 change created two control groups. The first group consists of states for which the maximum interest rate was $36 \%$ before the change and thus has not changed subsequently. The second group contains the state of Texas for which the maximum interest rate caps have remained $10 \%$ and $18 \%$, depending on the purpose of the loan ${ }^{24}$ In addition, multiple treatment groups were created - a state that had a cap of $6 \%$ experienced a greater change than a state that had a cap of $21 \%$. I reduce the number of control and treatment groups by merging categories. The control group includes states in which the cap did not change. I divide treated states into three groups based on the interest rate cap clusters observed in Figure 6. I label states that had an interest rate cap of $24-25 \%$ as states with Low Intensity Treatment. States with a cap of $16-21 \%$ and 6-12\% are labeled as states with Medium and High Intensity

\footnotetext{
${ }^{24}$ To the best of my knowledge, there was no legal reason that could prevent Prosper from increasing the maximum interest rate for Texan borrowers to $36 \%$. One possible explanation for Prosper's decision to keep a lower cap is that Prosper or Prosper's charting renting bank partner had informal discussions with bank regulators in Texas, and were concerned that circumventing Texas law was more politically risky than circumventing the laws of other states.
} 
Treatments, respectively. The specification corresponding to the groups defined above is

$$
\begin{aligned}
Y_{i t}=\beta_{0}+\beta_{1} \cdot I_{t}^{\text {After }}+ & \beta_{2} \cdot I_{i}^{\text {Low Intensity Treat. }}+\beta_{3} \cdot I_{i}^{\text {Med. Intensity Treat. }}+ \\
& \beta_{4} \cdot I_{i}^{\text {High Intensity Treat. }+} \\
& \beta_{5} \cdot I_{t}^{\text {After }} \cdot I_{i}^{\text {Low Intensity Treat. }}+\beta_{6} \cdot I_{t}^{\text {After }} \cdot I_{i}^{\text {Med. Intensity Treat. }}+ \\
& \beta_{7} \cdot I_{t}^{\text {After }} \cdot I_{i}^{\text {High Intensity Treat. }}+\epsilon_{i t}
\end{aligned}
$$

where $I_{t}^{\text {After }}$ indicates whether listing $i$ was posted after April 15, 2008. $I_{i}^{\text {Low Intensity Treat. }}$

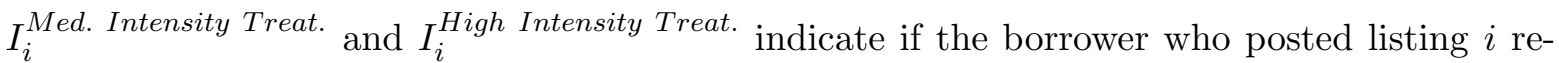
sides in a treated state that had its pre change interest rate restriction in the range of $24-25 \%$, $16-21 \%$ and $6-12 \%$, respectively. $Y$ is the outcome variable on which the treatment effect is estimated.

I enrich the specification by including a set of week and state indicators. Thereby controlling for any effect that is constant within a week (rather than within the time period before or after the change) or that is constant within a state (rather than within a group of states that had a similar cap before the change). It should be noted that the new specification makes redundant the previously included indicators for after the change and for each type of treatment group. In addition, the inclusion of a listing's characteristics control for other differences between listings. The resulting specification is

$$
\begin{aligned}
Y_{i t}= & \gamma_{0}+\gamma_{1} \cdot I_{t}^{\text {Week }}+\gamma_{2} \cdot I_{i}^{\text {State }}+\gamma_{3} \cdot I_{t}^{\text {After }} \cdot I_{i}^{\text {Low Intensity Treat. }}+ \\
& \gamma_{4} \cdot I_{t}^{\text {After }} \cdot I_{i}^{\text {Med. Intensity Treat. }}+\gamma_{5} \cdot I_{t}^{\text {After }} \cdot I_{i}^{\text {High Intensity Treat. }}+\gamma_{6} \cdot h\left(X_{i t}\right)+\epsilon_{i t}
\end{aligned}
$$

where $I_{t}^{\text {Week }}$ is a vector of week dummies, and $I_{i}^{\text {State }}$ is a vector of state dummies. The omitted week is naturally taken to be the week just before the April 15 change. The omitted group of states consists of all states in the control group. $X_{i t}$ is a vector with the characteristics of the listing.

It should be emphasized that while the interest rate a borrower faces is used to define his association with a treatment or control group, a borrower need not set his maximum willingness to pay as high as the interest rate cap he faces. Borrowers are potentially heterogenous in their 
bidding function which maps the interest rate cap they face to their maximum willingness to pay. Nonetheless, the empirical strategy is neither aimed at modeling the borrower's bidding function nor its effects; thus I do not use the maximum willingness to pay throughout the analysis. In Figure 7, I present evidence on potentially heterogeneity in borrowers' bidding function.

\subsection{Heterogenous Treatment Effects}

The empirical strategy described so far has focused on estimating the average treatment effect. Nonetheless, economic theory suggests that the treatment effect may depend on the risk level associated with a borrower. For example, a high-risk borrower that is bound by the interest rate cap is expected to have a greater treatment effect than a low-risk borrower for whom the interest rate cap is not restricted ${ }^{25}$

Therefore, the empirical strategy is extended to account for heterogenous treatment effects based on borrowers' risk levels - a continuous latent variable. I use the credit grade letter assigned by Prosper to each potential borrower as a proxy for the risk level. Credit grades can serve as good proxies since they are salient to lenders and are used as a natural way to sort borrowers. The result is the following extended estimation equation -

$$
\begin{aligned}
& Y_{i t}=\eta_{0}+\eta_{1} \cdot I_{t}^{W e e k}+\eta_{2} \cdot I_{i}^{\text {State }}+\sum_{g \in(A, B, \ldots, H R)} \eta_{\text {Grade } g} \cdot I_{i}^{\text {Grade } g}+ \\
& \sum_{j \in(\text { High,Med.,Low })} \eta_{\text {After }, j \text { Intensity Treat. }} \cdot I_{t}^{\text {After }} \cdot I_{i}^{j \text { Intensity Treat. }}+ \\
& \sum_{g \in(A, B, \ldots, H R)} \eta_{\text {After }, \text { Grade } g} \cdot I_{t}^{\text {After }} \cdot I_{i}^{\text {Grade } g}+ \\
& \sum_{\substack{j \in(\text { High,Med.,Low }) \\
g \in(A A, A, B, \ldots, H R)}} \eta_{j \text { Intensity Treat.,Grade } g} \cdot I_{i}^{j} \text { Intensity Treat. } \cdot I_{i}^{\text {Grade } g}+ \\
& \sum_{\substack{j \in(\text { High,Med.,Low }) \\
g \in(A, B, \ldots, H R)}} \eta_{\text {After }, j \text { Intensity Treat.,Grade } g} \cdot I_{t}^{\text {After }} \cdot I_{i}^{j \text { Intensity Treat. }} \cdot I_{i}^{\text {Grade } g}+ \\
& \eta_{3} \cdot h\left(X_{i t}\right)+\epsilon_{i t}
\end{aligned}
$$

where the first difference effects - on time, state and grade - are included in the first line of the

\footnotetext{
${ }^{25}$ The treatment effect may depend on the slope of the supply curve. Section 4.5 discusses this issue.
} 
equation. The second through the fourth lines of the equation contain the second differences. The fifth line contains the main parameters of interest, namely, the effects of the interest rate restriction on each treatment group and credit grade combination.

\subsection{Selection into the Pool of Borrowers}

Most previous studies on the effects of usury laws that are based on individual-level data do not credibly solve the problem of selection into the pool of potential borrowers. The following scenario illustrates this situation. Consider a potential borrower that faces a cap of $12 \%$. If he has low expectations to be funded, he may find it sub-optimal to post his listing due to the opportunity cost associated with the time it takes to post a listing (approximately 30 minutes). Alternatively, the increase in the ceiling rate may drive new borrowers ("entrants") to post their listings because they have higher expectations to be funded. Nonetheless, "entrants" are likely have a lower funding probability than "incumbents". As a result, a researcher may wrongly conclude that the increase in the interest rate cap results in a decrease in a listing's funding probability whereas in reality, any listing has a higher funding probability, but the composition of listings has changed.

Typically, the econometrician observes data on individuals that apply for loans before and after the change. Hence, he can control for the different characteristics of potential borrowers. If he were to do it perfectly, then he would be able to separate between the effect of the change in the cap, and the effect of a change in the pool of borrowers. In reality, however, there is a gap between the information utilized by lenders and the information observed by the econometrician. This gap restricts the econometrician's ability to correctly perform the counterfactual of predicting the outcome under the original interest rate cap of "entrants" that are observed only after the change. As a result, selection usually is not fully controlled.

Fortunately, in my study the data set in hand contains almost every piece of information that lenders could have observed in the process of making their bidding decision. Put another way, any information that I do not observe could not have affected all the lenders in any case. Therefore, controlling the information on borrowers in a flexible way would eliminate selection. Ideally, I would like to estimate the probability of a potential borrower to post a listing. However, I observe only listings that were actually posted, a fact that make the 
estimation of the posting probability infeasible. But since potential borrowers' decision to post a listing is affected by their probability to be funded, I can use the data to control for the probability of a listing to be funded, and by this eliminate the selection problem.

\subsection{Outcome Variables}

In the following sections I investigate the effect of interest rate restrictions on four groups of outcome variables: 1) The probability of a listing to be funded; 2) the amount a borrower requests; 3) the APR a borrower pays and 4) loan repayments variables including the probability of default, the number of late payments, the probability that all payments are paid on time and the probability the the latest observed payment is paid on time.

First, it should be noted that the probability of a listing to be funded is a binary variable. This suggests that a probit specification is appropriate for the estimation. Second, the amount requested by a borrower is a continuous variable that ranges from $\$ 1,000$ to $\$ 25,000$. Hence, I use a two-sided Tobit model to estimate how interest rate restriction affects the amount requested. Third, the APR paid by a borrower is a continuous variable that is bound to be below the interest rate cap. Hence, it is most natural to use a one-sided Tobit specification. Fourth, loan repayment variable are binary or discrete. Thus, a linear probability model and poisson model are used for the analysis of loan repayments.

\subsection{General Equilibrium Effects}

Since its introduction, Prosper has mediated loans for a total amount exceeding $\$ 175,000,000$. This large amount only accounts for less than $0.0025 \%$ of the US consumer credit loans 26 Hence, if Prosper had been perfectly integrated into the consumer loans market, then the April 15 change would have been expected to redirect credit from other loan markets into the Prosper marketplace. If this were the case, borrowers would not be expected to pay a higher APR as a result of the higher volume of loan requests. However, it is not at all clear that Prosper is indeed perfectly integrated into other consumer loan markets. Specifically, Prosper's position as a relatively new marketplace that operates in an online setting may make its integration process into other credit markets slower. The distinction of whether Prosper

\begin{tabular}{lllllll}
\hline${ }^{26}$ See the Federal Reserve Statistical & Release & on & consumer & credit & - \\
http://www.federalreserve.gov/releases/g19/Current/.
\end{tabular}


is well or poorly integrated into consumer loan markets is reflected by the slope of the credit supply curve in the Prosper marketplace; a perfectly elastic supply curve is the manifestation of being well integrated, whereas an increasing supply curve indicates that this marketplace, to some extent, operates separately from other consumer loan markets.

I conduct two tests of the null hypothesis that the supply curve is perfectly elastic. The first test is based on the treatment effect of the price paid by borrowers. The second is based on the treatment effect of the funding probability. A perfectly elastic supply curve implies a zero price effect of the April 15 change on all categories. Furthermore, it implies that the funding probability is unchanged in categories that were unaffected by the treatment. Specifically, borrowers in the control group and in treatment groups that were not bounded under the original cap should not have experienced a change in their funding probability.

The tests described are limited since they do not distinguish between upward sloping supply curve and generic time effects. Namely, a rejection of the null hypothesis can be interpreted as evidence for an upward sloping supply curve if I assume that nothing else occurred during that time that affected differently two credit grades within any treatment group. Alternatively, a rejection of the null is to be considered as evidence for generic time effect under the assumption of perfectly elastic supply curve.

\section{Basic Evidence}

I focus on differences over time and between treatment and control groups, and differentiate between credit grades. I abstract from potential time effects by focusing on a narrow time window of one month before and one month after the change. I present data on the control group and on the group of borrowers that experienced the largest treatment - a change from an interest rate cap in the $6-12 \%$ range to an interest rate cap of $36 \%$. Within each group, I only present data on a subset of the credit grades ${ }^{27}$ For each category, I present the main outcome variables of interest - number of listings and loans together with the mean values of the amount requested, the funding probability, the price paid by borrowers and loan repayment variables. Loan repayment variables include the default probability, the average number of late

\footnotetext{
${ }^{27}$ The patterns presented carry through even when I consider an additional two months that are further away from each other. In addition, inclusion of more treatment groups or more credit grades do not provide additional insights.
} 
payments, the probability that all 18 payments that are used in the repayment analysis were paid and the probability that the $18^{\text {th }}$ payment was paid.

The results are presented in Table 3 and Table 4 . Table 3 includes the amount requested, the funding probability and the loan interest rate. Table 4 summarizes the repayment variables. Table 3 reveals a greater increase in the number of listings posted in the treatment group.

The funding probability in the control group decreases in all credit grades, whereas a reverse pattern is exhibited in the treatment group. If the supply curve is upward sloping, the different patterns between the treatment and control groups can be explained by the de facto shift in the aggregate demand as a result of the increase in the maximum allowed rate in the treatment groups. In addition, these findings can be interpreted as evidence for different time effects across the two groups.

Figure 8 contains a graphical illustration of the changes in the funding probability by credit grades and across the treatments and control groups. Specifically, the vertical difference between the two lines in the upper left figure corresponding to the control group exhibits a negative time trend in the funding probability. The vertical differences in the other figures which is in excess of the time trend correspond to the treatment effects. The fact that each treatment group has a different initial interest rate cap explains why a different credit grade within each treatment group experience the greatest change in the funding probability.

The average amount requested does not exhibit major changes over time within any group. The APR observed in the control group is slightly changed over time. On the contrary, the APR observed in the treatment group is elevated for the lower credit scores. One possible reason for the higher APR is the change in the composition of borrowers since high risk borrowers with potentially different observed characteristics have their loans funded under the elevated cap. Loan repayment variables exhibit deteriorating repayment patterns over time both in the control and in the treatment groups. The negative patterns, however, are amplified in the treatment group. These findings should be considered with cautious due to the small number of loans originated in the month prior to the change in the control group. 


\section{Empirical Analysis}

The evidence presented in Section 5 does not account for changes in the composition of listings posted under different interest rate caps. The analysis presented below fills this gap. The analysis is based on variants of equation (3) that are tailored to the specificities of each outcome variable of interest.

I begin by studying how the probability of a listing to be funded is affected by the April 15 change. I employ a Probit model based on equation (3) with the dependent variable being an indicator for whether a listing was funded. I present the estimated treatment effects in Table 5. The four specifications differ by the extent and the flexibility in which selection is accounted for. The first specification does not account for any characteristics of the listing apart from the the borrower's state and the week of posting. The second specification includes financial information provided by Prosper as described in Appendix A. The third specification relaxes the linearity of key financial variables as described in Appendix B by allowing their effect to change over their distribution. Information provided by the borrower on his financial situation and the purpose of the loan as described in Appendix Cis controlled in the fourth specification. I supplement the table by including the empirical funding probabilities prior to the April 15 change as a benchmark. To ease the understanding of the table, Figure 9 contains a graphical representation of the results from the fourth specification. In the graph the point estimates and the $95 \%$ confidence interval of the treatment effect for each category are drawn. The same qualitative results are observed in all specifications, even though additional regressors are added. The coefficients should be interpreted as the expected increase in the funding probability. Increasing the cap from $24-25 \%$ to $36 \%$ increases the funding probability by up to 0.1 . The expected increments in the funding probabilities of listings from the treatment groups that had a cap of $6-12 \%$ and $16-21 \%$ are 0.6 and 0.3 , respectively.

The table provides two insights. First, the treatment effect is significantly positive in categories that could have benefited from an increase in their cap. That is, categories that had an interest rate restriction that was more binding than the interest rate restriction in their counterpart control group categories. Second, the greatest treatment effect within a treatment group is estimated for a different credit grade. For the purpose of discussing the results, I define a credit grade to be restricted under an interest rate cap if the cap is lower than the 
average interest rate in the control group for the same credit grade before the April 15 change.

Figure 10 contains the average APR in the control group before the April 15 change for all credit grades and horizontal lines that mark the highest cap in each treatment group. The figure identifies the credit grades that are restricted in each treatment group and therefore expected to have a positive treatment effect. For example, borrowers with credit grades $\mathrm{E}$ and HR were restricted under a cap of $25 \%$. This fact suggests that positive treatment effects are expected to be estimated for these credit grades as a result of the increase in the cap from $25 \%$ to $36 \%$.

The vertical differences between the two funding probability lines in Figure 8 provide an explanation for the finding that the greatest treatment effect in each treatment group is estimated at a different credit grade. For example, the observation that the vertical difference in the lower right figure is greatest for credit grade B coincides with the finding that among borrowers who faced a cap of $6-12 \%$, credit grade B borrowers are estimated to have a treatment effect greater than other credit grades.

The amount a borrower requests in a listing is a major determinant of its probability to get funded. The parameter estimates of specification (3) reveal that for the average listing, the funding probability decreases by $4.5 \%$ for a $1 \%$ increase in the amount requested 28 Even though I control for the amount in the analysis of the treatment effect of the amount requested, one might be concerned that the amount requested is endogenous in the sense that borrowers tailor the amount they request according to the interest rate cap. I address this concern by estimating the treatment effect on the amount a borrower requests. I use a two-sided Tobit model since the amount requested is bound to be in the range of $\$ 1,000$ - $\$ 25,000$. The marginal effects are presented in Table $6{ }^{29}$ The same four specifications that were employed to study the treatment effect on the funding probability are estimated. The results are robust to the specification chosen. The treatment effects are insignificant in 16 out of the 21 categories analyzed. Yet, I can reject the null hypothesis of zero treatment effect (P-value $<0.001)$.

\footnotetext{
${ }^{28}$ Specification $(3)$ allows for non-linear effects of the amount requested on the funding probability. The effect is allowed to differ over the quartiles of the amount. The corresponding z-stats. are in the range of 31.2-38.1.

${ }^{29}$ The Tobit parameters ( $\beta$ and the standard deviation of the Tobit error term $\sigma$ ) are estimated through maximum likelihood. The estimated coefficients are then used to estimate the marginal effect on the latent amount requested conditional on the latent amount being in the range $\$ 1000-25000-\frac{\partial E[y \mid y \in[1000,25000], x]}{\partial x_{k}}=$ $\beta_{k}\left(1-\lambda\left(\frac{x \beta}{\sigma}\right)\left[\left(\frac{x \beta}{\sigma}\right)+\lambda\left(\frac{x \beta}{\sigma}\right)\right]\right)$. Where $\lambda(\cdot)=\frac{\phi(\cdot)}{\Phi(\cdot)}$ is the inverse Mills ratio. The marginal effects are estimated at the sample average point. Standard errors are estimated using the delta method.
} 
I provide a graphical illustration of the last specification estimates and the $95 \%$ confidence interval in Figure 11

I proceed by investigating the effect of interest rate cap on the APR. The specification employed is the one previously used. A natural way to estimate the treatment effect is to use a loan's APR as the dependent variable. The problem, however, is that ignoring nonfunded listings generates a problem of selection on the dependent variable because the APR is bound to be below some value. Therefore, I use the information embodied not only in loans, but also in non-funded listings. The dependent variable is the APR for loans and the interest rate cap for non-funded listings. The model being used is a one-sided Tobit model. The implicit assumption employed is that non-funded listings would have been funded under a higher interest rate cap. That is, their cap is treated as a lower bound on the APR.

A major concern is that many of the listings would have been funded only for a very high APR. Consequently, the location within the "true" APR distribution of a high fraction of the listings is far away to the right, implying fat tail of the APR distribution. This fact makes the estimates sensitive to the proportion and the extent to which the listings are censored. I resolve this problem by eliminating listings with a very low funding probability. Specifically, I choose a predicted funding probability of 0.1 to be the threshold below which observations are eliminated ${ }^{30}$ I present the marginal effects in Table 7, and provide a graphical illustration of point estimates and the $95 \%$ confidence interval in Figure 12. The analysis suggests that the treatment effects on the interest rate are in general close to zero. While some categories exhibit significant positive treatment effects, none exceed $1.3 \%$, and the effect is significantly positive only in 5 out of the 16 categories for which it is estimated. These findings imply that an increase in the cap is likely not to cause any change in the APR, or at the most drive a minor increase in the APR. Recall that an increase in the APR is expected if lenders have market power or if the supply of credit is upward sloping. Below I provide evidence as to which of the two might be the driving force of any increase.

\footnotetext{
${ }^{30}$ I use observations from before April 15, 2008 to estimate a Probit model of the probability of a listing to get funded. The model estimates are then used to predict the funding probability of listings posted before and after April 15. Focusing on listings with a funding probability greater than 0.1 eliminates 72,786 listings of which only 1,056 were funded. I also experiment with values different than 0.1 for the threshold such as $0.05,0.2,0.3$ and 0.4. I find that following the elimination of listings with low funding probability, the estimated treatment effects in categories with very few observations are sensitive to the threshold chosen. The estimation results are, nonetheless, robust in those categories with more observations - mainly the higher credit score categories.
} 
I first investigate whether riskier loans are originated if one controls for the characteristics of the loan. I use information about the first 18 payments for all originated loans ${ }^{31}$ Repayment history is in general complicated. To simplify the analysis, I estimate the treatment effects on several outcome variables representing various aspects of the repayment history. The first outcome variable analyzed indicates if the borrower pays the first 18 payments. The second indicates whether the $18^{t h}$ payment is paid. The third variable counts the number of missing payments out of the first 18 payments. The last variable is a default indicator defined as being more than four payments behind. In order to account for selection of loans that is based on observables into the sample, I include each loan's predicted funding probability as a regressor using the estimates presented in Figure $93^{32}$ A zero treatment effect can be expected since I condition on the characteristics of the loan, and find that the interest rate is unchanged. The estimates are presented in Table 8. Each column presents the treatment effect estimates on a different loan repayment variable. I use a linear probability model for binary outcome variables and a Poisson model when the effect on the number of late payments is studied 33 The point estimates and the $95 \%$ confidence intervals from the regressions are drawn in Figures 13,16. The insignificance of the treatment effects is robust to the outcome variable examined. Furthermore, I cannot reject the null hypothesis that all the treatment effects are zero. (P-values are 0.28, 0.05, 0.18 and 0.10)

I invoke the positive correlation test that is common in the insurance markets literature in order to evaluate the extent of selection of borrowers based on variables that are unobservable to lenders. The basic idea of the test is that conditional on observables, a positive correlation between the amount of insurance purchased and the ex-post occurrence of insured risk implies information asymmetry ${ }^{34}$ Similarly, the observation that conditional on observables, there is

\footnotetext{
${ }^{31}$ While most loans are more than 18 months old, using information about the first 18 payments allows to incorporate all the loans into the analysis.

${ }^{32}$ I use the Murphy-Topel standard errors adjustment to account for the fact that the funding probability is a generated regressor (See Hardin (2002) for details on the adjustment).

${ }^{33}$ The first model that comes to mind for a binary outcome variable is a Probit model. As demonstrated in Table 3 some of the categories that had only few loans originated prior to April 15, 2008 had no variability in the loan repayment variables. As a result, the dependent variable of these loans is perfectly predicted by the loan category dummies. This problem is known as quasi-complete separation (see Zorn (2005) and Silva and Tenreyro (2009) for a discussion of the problem in binary and count models, respectively). Estimation of both Probit and Poisson models result in very high estimates for some parameters and their standard deviations. Hence, I use a linear probability model instead of a Probit model and follow the method described in Silva and Tenreyro (2009) to remove the problematic regressors from the Poisson model.

${ }^{34}$ See Chiappori and Salanie (2000) for the original statement of the test.
} 
no correlation between loan repayment and the interest rate cap suggests that selection on unobservables is not a problem in evaluating other effects of interest rate caps 35

To get a sense of the cumulative effects of the increase in the interest rate caps, a simple back-of-the-envelope calculation is performed. I use post April 15 data together with the estimated treatment effects to calculate what would be the number of loans, the total amount lent and the total amount repaid by borrowers if the interest rate caps would remained unchanged. I find that the number of loans originated in Prosper in the year following April 15, 2008 would be lower by 4,250 if the interest rate cap would not have increased. This decrease in the number of loans accumulates to a decrease of almost 30 million dollars in allocated credit. In addition, unchanged interest rate caps would be translated to a modest decrease of only 400 thousand dollars in credit repayment compare to the amount that would be paid under higher caps ${ }^{36}$

To test the null hypothesis that the supply curve is perfectly elastic, I implement the tests described in Section 4.5 using the estimated treatment effects. I conduct two tests. In the first, I test whether treatment effects for all credit grades in the treatment groups as well as changes in the APR in the control group are 0. In the second test I assume that as reflected in Figure 10, borrowers with credit grade AA were not restricted in the low and medium treatment intensity groups. Similarly, borrowers with credit grade A were not restricted in the low intensity treatment group. I perform a joint test for zero treatment effects in those non-restricted categories and a zero change in the funding probability in the control group. I reject both tests and conclude that the supply curve of credit is not perfectly elastic. (The P-values of both tests are less than 0.001)

\section{Robustness Tests}

The institutional details of Prosper combined with some of the assumptions taken throughout the analysis suggest that the robustness of the findings should be examined. In each subsection

\footnotetext{
${ }^{35}$ Iyer, Khwaja, Luttmer, and Shue (2009) demonstrate that lenders in Prosper infer borrower's credit worthiness using the non-verified information provided by the borrower. This ability of the lenders to use non-verified information supports the finding presented here of no information asymmetry.

${ }^{36}$ The calculation of the change in the total amount repaid involves a few simplifying assumptions. First, I ignore the treatment effects in loan repayment. As demonstrated above, these effects are insignificant. Second, I keep the number of loans originated unchanged. Third, I assume that loans are fully repaid.
} 
below, I describe a specific concern, the test conducted to address it and its result.

\subsection{Generic Time Effects}

The method of differences-in-differences identifies causal effects if one assumes that conditional on covariates, the time trend is similar across groups. One might suspect, however, that the time trend in general varies across states, and that lenders take these changes into account. For example, information regarding elevated financial stress in the auto industry that has revealed around April 2008 may adversely affect Michiganite borrowers. If the estimation is performed as if the time trend is state invariant, the estimated treatment effects would underestimate the effect of the cap increase from the original $25 \%$ interest rate cap in Michigan to $36 \%$. Below I suggest two ways to address this concern.

First, I enrich the specification with macro variables that can capture differences in time trends across states. I focus on variables that are posted regularly at the state level and that are potentially reflected in the time trend if they are not included. The variables included are the monthly unemployment rate, the change in the unemployment rate and the quarterly per person number of bankruptcy filling. I compare the estimates of the treatment effect on the funding probability in a specification that includes the macro variables with the estimates of the baseline specification (graphed in Figure 91. I find that the two sets of estimates are almost identical, and that among the three macro variables included, only the coefficient on the bankruptcy variable is significant.

Second, I attempt to abstract from time trends by focusing on a narrow time window around April 15, 2008. Time effects are redundant if the time window is narrow enough. The problem, however, is the lack of sufficient variation in the data needed to estimate the baseline specification when the time window is very narrow. In addition, a reduction in the number of observations yields noisier estimates. Hence, I use a time window of one month before and after April 15, 2008. This time window has enough variation needed to estimate the baseline specification. Figure 17 features the point estimates and the $95 \%$ confidence intervals obtained from a sample that is restricted to a 60-day time window around April 15, 2008. While the estimates obtained in the restricted sample are noisier, the overall pattern is similar. The evidence provided here suggests that the assumption that the time effect in Prosper is state 
invariant is not restrictive.

\subsection{Amount Dependent Interest Rate Cap}

While the interest rate caps in most states are fixed, other states restrict their caps being amount-dependent 37 As a result, the observed interest rate cap partially reflects borrowers' response through adjustments of the amount they request ${ }^{38}$ I resolve this problem by forming simulating instruments for the amount requested. The idea is to exploit the variation in state interest rate caps, and not the variation generated by the endogenous decisions on the amount. I instrument for the amount requested with the value this variable would take if the decision regarding the amount would not be affected by the interest rate cap. This is done using post April 15 data when no state had its cap being amount-dependent ${ }^{39}$ Addressing the endogeneity of the amount requested is prima facie important since borrowers from multi-cap states post $22 \%$ (27\%) of the listings (loans) in Propser prior to April 15. Nonetheless, the use of simulated instruments changes the association of borrowers with their original treatment group for only $4 \%$ (3.5\%) of the pre-April 15 listings (loans). Therefore, it is not surprising that the differences between the treatment effects estimated using simulated instruments (not presented here) and the treatment effects estimated in the baseline specification are tiny.

\subsection{Listing reposting}

Borrowers at Prosper are allowed to repost a listing if the auction on their previous listing ended and the listing was not fully funded or if they withdrew their listing before the auction ended. A borrower who reposts a listing can change the content of the listing that he generated such as the amount requested, maximum willingness to pay, photo and listing narrative. Presumably, a

\footnotetext{
${ }^{37}$ For example, the interest rate cap in California is $19.2 \%$ for loans of $\$ 1000-\$ 2550$ and $36 \%$ for loans of higher amounts. Other states with amount dependent caps are Arizona, Kentucky, Maine, Massachusetts, Minnesota and New Hampshire.

${ }^{38}$ This relationship between the amount requested and the interest cap creates a problem of endogeneity. The reason is that these two variables are simultaneously determined. As a result, the cap is endogenous when the dependent variable is the amount requested. Furthermore, for the other dependent variables, a borrower may alter the amount he requests in order for a different cap to be applied, making the amount requested endogenous.

${ }^{39}$ I estimate a Tobit model using post April 15 data (excluding borrowers from Texas) in which the cap is set to $36 \%$ for all borrowers. I use the model estimates to predict the amount requested by borrowers prior to this date, and then use the simulated amount to determine the cap to be applied prior to April 15 to borrowers from multi-cap states. Finally, I re-estimate the baseline specification using the simulated amounts and interest rate caps.
} 
borrower positions his listing better in later reposts. As a result of borrowers' ability to repost, one might suspect that the observed listings are heterogenous with respect to the borrowers' ability to optimally position their loan requests. While some borrowers have their first listing being optimally positioned and phrased, others need to repost it several times to achieve optimality. I would like to disentangle the effect of the interest rate cap from the effect of the borrower's ability to assemble an attractive listing. To do this, I account for this heterogeneity by focusing on listings that are more likely to be optimally positioned. Specifically, I define a borrower's repost episode as a sequence of listings posted by the same borrower in which each listing (except for the first) is posted a short time after the the previous listing was expired or withdrawn. I include only the latest listing in each repost episode. I repeat the analysis for various thresholds each constitutes an upper limit on what short time is 40 Table 9 includes the numbers of borrowers and loan requests that are part of repost episodes for the various thresholds. I estimate the baseline specification on the listing funding dummy as the dependent variable restricting the sample to include only the latest listing in each repost episode. The estimated treatment effects (not presented here) are almost identical to those estimated using the full sample, which suggests that the findings are robust to this specific institutional detail.

\subsection{Placebo Test}

One might suspect that the driving force of the findings is not the increase in the interest rate cap that took place at Prosper, but rather another unobserved change. If this is the case, the documented effects can be at most only partially attributed to the cap increase. In order to test whether other change with similar effects has taken place I conduct a placebo test. I use data from either before or after April 15, 2008. I randomly draw a date and estimate the baseline specification on the listing funding dummy as if the unobserved change had taken place on that date 41 I conduct 200 repetitions of this procedure. I find that on average only 1.75 of the 21 estimated treatment effects on the funding probability are significant at the $5 \%$ level,

\footnotetext{
${ }^{40}$ I experiment with 12,24, 48, 72, 120 and 240 as the maximal number of hours between a listing expiration or withdrawal and posting of a listing by the same borrower. These figures are used to define repost episodes.

${ }^{41}$ Technically, I set the variable $I_{t}^{\text {After }}$ equal to 1 if a listing was posted after the randomly drawn date. Drawing a date that is very close to the beginning or the end of the sample period results in zero loans in some categories. As a result, the treatment effect on the funding probability for those categories cannot be estimated using a Probit model. Hence, I restrict the unobserved change to occur on 12/15/2007-03/15/2008 or $05 / 15 / 2008-08 / 15 / 2008$.
} 
whereas 17 of the treatment effects are found to be significant when the change is assumed to occur on April 15, 2008 42 A comparison between the two figures suggests that it is unlikely that another unobserved change drives the findings.

\section{Discussion and Conclusions}

Access to credit has been considered as a main springboard to economic development. The evolution of usury laws throughout history has positioned them as a government intervention in credit markets that is required in order to protect consumers from usury. This paper uses detailed individual-level data to evaluate the validity of this claim in a new yet fast-growing credit market, namely the online person-to-person credit market. I perform the evaluation by studying the effects of interest rate restrictions on the marketplace utilizing a change that increased the maximum interest rate allowed for a borrower to pay up to $36 \%$ in all US states but one.

The main findings are that borrowers who were restricted under their original cap benefit from the increase in the cap and the marginal borrower benefits the most. In addition, any borrower is expected to pay at most a slightly higher price for credit that is issued under a higher interest rate restriction. Last, loan repayment patterns remained unchanged. The main contribution of this research lies in its ability to identify the causal effects of interest rate restrictions. An additional contribution is that I provide evidence for an imperfect integration of the studied credit market with other credit markets.

The main challenges addressed here are the selection of borrowers into the sample and the isolation of causal effects from generic time effects that are unrelated to the change. Borrowers can be selected into the sample based on information that is observed or unobserved by lenders. Selection based on observables is taken into account by incorporating the information that lenders could observe when making their lending decisions. Selection based on unobservables (i.e. asymmetric information) is not an issue as the positive correlation test (no correlation between the interest rate cap and loan repayment) suggests. Isolating causal effects from generic time effects is accomplished by using a control group that did not experience a

\footnotetext{
${ }^{42}$ The number of significant treatment effects estimated in the placebo test ranges between $0-4$. Out of 200 repetitions preformed, no significant treatment effect was found in $16.5 \%$ of the repetitions. In $16 \%, 48.5 \%$, $16 \%$ and $3 \%$ of the repetitions the number of significant treatment effects are 1, 2, 3 and 4 , respectively.
} 
change in its interest rate cap.

It should be emphasized that the experiment studied in this paper is of an increase in the interest rate cap in a single credit market, rather than a simultaneous increase in the cap in many credit markets ${ }^{43}$ It is possible, nonetheless, to use the findings of this paper to hypothesize what would be the effects of a simultaneous change in the cap. Having the cap increased in a single credit market may have an adverse effect on the default probability, or any other repayment variable, in the credit market in which the cap is elevated relative to the default probability in other credit markets. The reason is that a borrower facing higher future payments for a loan originated in the credit market with the higher cap would opt to default on this loan, rather than on a loan with a lower cap since it is likely a more expensive loan. The effect of a simultaneous change, nevertheless, depends on how caps in different credit markets co-vary. If caps are positively correlated across markets, then a simultaneous increase in the caps is less likely to change the relative price of credit across markets. Thus, the treatment effect on the default probability that is estimated in this paper constitutes an upper bound on the effect of a simultaneous increase on the default probability. If caps, however, are negatively correlated or uncorrelated, the effect of a simultaneous increase in the cap on the default probability in a single credit market depends on changes in the relative price of credit in that credit market compared to its price in other credit markets.

In order to evaluate the extent to which regulation is correlated across credit markets, I use data on credit card interest rate caps and on individual bankruptcy exemptions. ${ }^{44}$ I find weak correlations between the interest cap used in Prosper before the April 15 change and credit card interest rate cap (0.093) and individual bankruptcy exemption (-0.028). These weak correlations suggest that the effect of a simultaneous increase in the caps in many markets might differ from the effect estimated in this paper.

There is a wide gap between a central argument in the debate over usury laws and one of the paper's findings. Proponents of usury laws claim that the price paid by borrowers would

\footnotetext{
${ }^{43} \mathrm{~A}$ simultaneous change is defined as a change in the interest rate caps that occurred concurrently in many credit markets in the same direction and magnitude.

${ }^{44}$ Gropp, Scholz, and White (1997) demonstrate the link between personal bankruptcy laws and credit prices. Data on credit card interest rate caps are taken from the American Bankers Association. Data on exemption was compiled by Mahoney (2009) based on the bankruptcy exemptions featured in Elias (2006). Bankruptcy exemption data indicate for each state, the average exemption individuals from that state are entitled to in case that they choose to file for bankruptcy. Individual exemptions are calculated based on households self reported balance sheets from the 2005 Panel Survey of Income Dynamics.
} 
substantially increase if usury laws were relaxed due to the market power lenders posses. In this paper, however, I find that borrowers are expected to pay only a slightly higher interest rates following an increase in the interest rate cap. This finding is not surprising given that the marketplace I study is highly competitive ${ }^{45}$ Thus, the findings do not preclude that borrowers in a less competitive credit market would experience a greater increase in their interest rates.

When examining this paper's findings one must take into consideration the effects of the recent financial turmoil on the findings. I use data on loan requests from November 2007 - September 2008, and data on loan repayments that span until April 2010. The financial crisis that began in July 2007 and has significantly deepened in September 2008. Hence, the effect of the crisis on loan origination is presumably constant over the time period used for the analysis. The aggravation in the crisis in September 2008 onwards may, however, dominate any cross-section heterogeneity in default rate which would make it harder to identify selection.

While Prosper is a new and unique marketplace, the findings of this paper are at least indicative of the effects of usury laws in other credit markets, especially those operating in similar conduct. The main takeaway point from this inquiry is that interest rate restrictions do not seem to deliver the outcomes for which they were intended.

\section{A Verified Variables}

Below I describe the variables that are included in the borrower's credit report.

- Auction Open For Duration - A dummy that is equal to 1 if the borrower chooses to end the auction when its duration ends and not before

- Home Owner - A dummy that is equal to 1 if the borrower is a home owner

- Amount Delinquent - The monetary amount delinquent

- Current Delinquencies - Number of accounts in which the borrower is currently late on payment

- Delinquencies in Last 7 Years - Number of $90+$ days delinquencies in the last 7 years

\footnotetext{
${ }^{45}$ Specifically, lenders' HHI is $0.04 \%$, and the largest lender is responsible only for $0.8 \%$ of the credit allocated.
} 
- Public Records Last Year - Number of negative public records in the borrower's credit report in the last 12 months

- Public Records Last 10 Years - Number of negative public records in the borrower's credit report in the last 10 years

- Inquiries Last 6 Months - Number of inquiries made by creditors to view the borrower's credit report in the last 6 months

- Bank Card Utilization - The percentage of available revolving credit that is utilized

- Current of Credit Lines in Last 6 Months - Number of reported credit lines in the last 6 months

- Revolving Credit Balance - Sum of balance on all open revolving credit lines in the last 6 months

- Total Credit Lines - The total number of credit lines appearing in the credit report

\section{B Variables Relaxed to Account for Non-Linear Effects}

Specifications 3-4 of Tables 5 5 and Specifications 1-4 of Table 8 allow for non-linear effects of several variables. In such cases, the effects depend on the value of the variable. The thresholds used to allow for different effects are based on the variables' median or quartiles values. Specifically, the variables and the thresholds used are:

- Amount Requested - with thresholds at $\$ 3000, \$ 5000$ and $\$ 10000$

- Current Delinquencies - with a threshold at 1 current delinquency

- Delinquencies in Last 7 Years - with a threshold at 3 delinquencies

- Inquiries Last 6 Months - with a threshold at 2 recent inquiries

- Bank Card Utilization - with a threshold at a utilization ratio of 0.75

- Current of Credit Lines in Last 6 Months - with thresholds at 4, 8 and 12 current credit lines 


\section{Non-Verified Variables}

The list below is a partial list of variables that are self-reported by borrowers. These variables are included in Specification 4 of Tables 5-77 as well as Specifications 1-4 of Table 8 .

- Dummy variables for the inclusion of each of the following words/phrases in the listings' title - help, credit card, debt, consolidate, start business, real estate, student, school, tuition, medical, doctor, fresh start, good guy

- Dummy variables for reported income within the following income ranges - up to $\$ 25 \mathrm{~K}$, $\$ 25 K-\$ 50 K, \$ 50 K-\$ 75 K, \$ 75 K-\$ 100 K$ and $\$ 100 K+$

- Dummy variables for each of the following employment statuses - not employed, retired, part time, self employed and full time

\section{References}

Alessie, R., S. Hochguertel, and G. Weber (2005): "Consumer Credit: Evidence From Italian Micro Data," Journal of the European Economic Association, 3(1), 144-178.

Benmelech, E., And T. J. Moskowitz (2010): "The Political Economy of Financial Regulation: Evidence from U.S. State Usury Laws in the 19th Century," The Journal of Finance, 65(3), 1029-1073.

Bentham, J. (1818): Defence Of Usury. Payne and Foss, London.

Blitz, R., And M. Long (1965): "The Economics of Usury Regulation," Journal of Political Economy, 73(6), 608-619.

Brown, J. L. (1992): "An Argument Evaluating Price Controls on Bank credit Cards in Light of Certain Reemerging Common Law Doctrines," Georgia State University Law Review, 9, 797-819.

Chiappori, P.-A., And B. Salanie (2000): "Testing for Asymmetric Information in Insurance Markets," Journal of Political Economy, 108(1), 56-78. 
Durkin, T. A. (1992): "An Economic Perspective in Interest Rate Limitations," Georgia State University Law Review, 9, 821-838.

Elias, S. (2006): The New Bankruptcy: Will it Work for You? Nolo Press.

Finchler, T. M. (1993): "Capping Credit Card Interest Rates: An Immodest Proposal," Annual Review of Banking Law, 12, 493-514.

Freedman, S., And G. Z. Jin (2008): "Dynamic Learning and Selection: the Early Years of Prosper.com," Discussion paper, University of Maryland.

Frierson, J. G. (1969): "Changing the Concepts of Usury: Ancient Times Through the Time of John Calvin," American Business Law Journal, 7(2), 115-125.

Glaeser, E. L., And J. Scheinkman (1998): "Neither A Borrower Nor A Lender Be: An Economic Analysis of Interest Restrictions and Usury Laws," The Journal of Law and Economics, 41(1), 1-36.

Goudzwandd, M. B. (1968): "Price Ceilings and Credit Rationing," Journal of Finance, 23(1), 177-185.

Greer, D. F. (1974): "Rate Ceilings, Market Structure, and the Supply of Finance Company Personal Loans," Journal of Finance, 29(5), 1362-1382.

(1975): "Rate Ceilings and Loan Turnover," Journal of Finance, 30(5), 1376-1383.

Gropp, R., J. K. Scholz, and M. J. White (1997): "Personal Bankruptcy and Credit Supply and Demand," The Quarterly Joutnal of Economics, 112(1), 217-251.

HARDin, J. W. (2002): "The Robust Variance Estimator for Two-Stage Models," The Stata Journal, 2(3), 253-266.

Hayeck, P. G. (1996): "An Economic Analysis Of The Justifications," Annual Review Of Banking Law, 15, 253-276.

Herzenstein, M., R. L. Andrews, U. M. Dholakia, and E. Lyandres (2008): "The Democratization of Personal Consumer Loans? Determinants of Success in Online Peer-toPerr Lending Communities," Discussion paper, University of Delaware. 
Homer, S., And R. Sylla (2005): A History of Interest Rates. John Wiley \& Sons Inc., fourth edn.

Iyer, R., A. Khwaja, E. Luttmer, and K. Shue (2009): "Screening in Alternative Credit Markets - Can Individual Lenders' Infer Borrower Credit-worthiness in Peer-to-Peer Lending?," Discussion paper, John F. Kennedy School of Government, Harvard University.

Mahoney, N. (2009): "Bankruptcy, Unpaid Care, and Health Insurance Coverage," Discussion paper, Working Paper, Stanford University.

Oeltuen, J. C. (1975): "Usury: Utilitarian or Useless?," Florida State University Law Review, $3,169-235$.

Persky, J. (2007): "Retrospectives: From Usury to Interest," Journal of Economic Perspectives, 21(1), 227-236.

Pope, D. G., And J. R. Sydnor (2010): "Whats in a Picture? Evidence of Discrimination from Prosper.com," Journal of Human Resources (forthcoming).

Pridgen, D. (2003): Consumer Credit and the Law. Thomson West.

Ravina, E. (2008): "Love \& Loans: The Effect of Beauty and Personal Characteristics in Credit Markets," Discussion paper, New York University.

Renuart, E., And K. E. Keest (2005): The Cost of Credit-Regulation, Preemption and Industry Abuses. National Consumer Law Center, Boston, MA.

Rougeau, V. D. (1996): "Rediscovering Usury: An Argument For Legal Controls On Credit Card Interest Rates," University of Colorado Law Review, 67, 1-46.

Shanks, H. (1967): "Practical Problems in the Application of Archaic Usury Statutes," Virginia Law Review, 53(2), 327-354.

Shay, R. P. (1970): "Factors Affecting Price, Volume, and Credit Risk in the Consumer Finance Industry," Journal of Finance, 25(2), 503-515. 
Silva, S., And S. Tenreyro (2009): "On the Existence of the Maximum Likelihood Estimates for Poisson Regression," Discussion paper, Department of Economics, London School of Economics.

Stegman, M. A. (2007): "Payday Lending," Journal of Economic Perspectives, 21(1), 169190.

Villegas, D. J. (1982): "An Analysis Of The Impact Of Interest Rate Ceilings," Journal of Finance, 37(4), 941-954.

(1989): "The Impact of Usury Ceilings on Consumer Credit," Southern Economic Journal, 56(1), 126-141.

Wallace, G. J. (1976): "The Uses Of Usury: Low Rate Ceilings Examined," Boston University Law Review, 56, 451-497.

Waterman, R. (1979): "Commercial Law. McConnell v. Merrill Lynch, Pierce, Fenner \& Smith, Inc.: Variable Rate Loans Under California's Usury Law," California Law Review, 67(3), 621-642.

Zorn, C. (2005): "A Solution to Separation in Binary Response Models," Political Analysis, 13(2), 157-170. 
Table 1: Summary Statistics - Prosper Provided Information

\begin{tabular}{|c|c|c|c|c|c|c|c|c|}
\hline & \multicolumn{4}{|c|}{ Super Prime } & \multicolumn{4}{|c|}{ Prime } \\
\hline & Mean & Std. & $10 \%$ & $90 \%$ & Mean & Std. & $10 \%$ & $\mathbf{9 0 \%}$ \\
\hline $\begin{array}{l}\text { \# Listings } \\
\text { \# Loans }\end{array}$ & $\begin{array}{l}11483 \\
2878\end{array}$ & & & & $\begin{array}{l}24898 \\
3860\end{array}$ & & & \\
\hline Listing Characteristics & & & & & & & & \\
\hline Amount & 13470 & 8074 & 3000 & 25000 & 9816 & 6284 & 3000 & 20000 \\
\hline Open For Duration & 0.94 & 0.23 & 1 & 1 & 0.92 & 0.28 & 1 & 1 \\
\hline Amount Delinquent & 922 & 19973 & o & 142 & 1557 & 7990 & o & 3183 \\
\hline Current Delinquencies & 0.30 & 0.96 & $\mathbf{0}$ & 1 & 0.91 & 2.07 & o & 3 \\
\hline Delinquencies Last 7 Years & 1.75 & 6.22 & $\mathbf{0}$ & 4 & 4.92 & 10.40 & o & 16 \\
\hline Public Records Last Year & 0.02 & 0.21 & 0 & o & 0.04 & 0.23 & o & 0 \\
\hline Public Records Last 10 Years & 0.24 & 0.85 & 0 & 1 & 0.38 & 0.86 & $\mathbf{0}$ & 1 \\
\hline Inquiries Last 6 Month & 2.12 & 2.87 & o & 5 & 2.97 & 3.54 & $\mathbf{0}$ & 7 \\
\hline Bank Card Utilization & 0.35 & 0.29 & $\mathbf{0}$ & 1 & 0.60 & 0.33 & o & 1 \\
\hline Current Credit Lines & 11.65 & 6.50 & 4 & 20 & 11.00 & 6.56 & 4 & 20 \\
\hline Revolving Credit Balance & 28749 & 60327 & 154 & 74467 & 24950 & 46843 & 272 & 62638 \\
\hline Total Credit Lines & 28.24 & 15.06 & 11 & 48 & 28.26 & 15.37 & 10 & 48 \\
\hline Listing Outcomes & & & & & & & & \\
\hline $\operatorname{Pr}$ (Funding) & 0.251 & & & & 0.155 & & & \\
\hline APR & $11.70 \%$ & $4.67 \%$ & $7.00 \%$ & $17.45 \%$ & $17.70 \%$ & $6.07 \%$ & $11.05 \%$ & $26 \%$ \\
\hline $\operatorname{Pr}($ All First 18 Payments Paid) & 0.847 & & & & 0.747 & & & \\
\hline Pr(18th Payment Paid) & 0.958 & & & & 0.933 & & & \\
\hline \# Late Payments & 0.559 & 1.828448 & 0 & 4 & 0.921 & 2.690362 & 0 & 4 \\
\hline $\operatorname{Pr}($ Default) & 0.116 & & & & 0.196 & & & \\
\hline
\end{tabular}

\begin{tabular}{|c|c|c|c|c|c|c|c|c|}
\hline & \multicolumn{4}{|c|}{ Sub Prime } & \multicolumn{4}{|c|}{ Total } \\
\hline & Mean & Std. & $10 \%$ & $90 \%$ & Mean & Std. & $10 \%$ & $90 \%$ \\
\hline General & & & & & & & & \\
\hline \# Listings & 78521 & & & & 114902 & & & \\
\hline \# Loans & 3231 & & & & 9969 & & & \\
\hline Listing Characteristics & & & & & & & & \\
\hline Amount & 5771 & 5256 & 1500 & 12500 & 7417 & 6380 & 1800 & 17000 \\
\hline Open For Duration & 0.84 & 0.36 & 0 & 1 & 0.87 & 0.34 & 0 & \\
\hline Amount Delinquent & 4337 & 14926 & 0 & 11510 & 3394 & 14419 & 0 & 9030 \\
\hline Current Delinquencies & 4.00 & 5.14 & 0 & 10 & 2.96 & 4.63 & 0 & 9 \\
\hline Delinquencies Last 7 Years & 12.68 & 17.55 & 0 & 35 & 9.91 & 15.97 & 0 & 30 \\
\hline Public Records Last Year & 0.09 & 0.37 & 0 & 0 & 0.07 & 0.33 & 0 & 0 \\
\hline Public Records Last 10 Years & 0.72 & 1.26 & 0 & 2 & 0.60 & 1.16 & 0 & 2 \\
\hline Inquiries Last 6 Month & 4.18 & 4.85 & 0 & 10 & 3.71 & 4.49 & 0 & 9 \\
\hline Bank Card Utilization & 0.70 & 0.45 & 0 & 1 & 0.64 & 0.42 & 0 & 1 \\
\hline Current Credit Lines & 7.77 & 5.84 & 2 & 16 & 8.86 & 6.28 & 2 & 17 \\
\hline Revolving Credit Balance & 8895 & 22495 & 0 & 21370 & 14359 & 35360 & 0 & 33951 \\
\hline $\begin{array}{l}\text { Total Credit Lines } \\
\text { Listing Outcomes }\end{array}$ & 26.16 & 14.72 & 9 & 45 & 26.82 & 14.93 & 9 & 46 \\
\hline $\operatorname{Pr}$ (Funding) & 0.041 & & & & 0.087 & & & \\
\hline & $25.68 \%$ & $7.82 \%$ & $15.50 \%$ & $35.00 \%$ & $18.56 \%$ & $8.41 \%$ & $9.00 \%$ & $34 \%$ \\
\hline $\operatorname{Pr}($ All First 18 Payments Paid) & 0.674 & & & & 0.752 & & & \\
\hline Pr(18th Payment Paid) & 0.925 & & & & 0.938 & & & \\
\hline \# Late Payments & 1.197 & 3.179835 & 0 & 4 & 0.907 & 2.663109 & 0 & 4 \\
\hline $\operatorname{Pr}($ Default) & 0.262 & & & & 0.194 & & & \\
\hline
\end{tabular}

The tables contains summary statistics of the variables provided by Prosper. The variables are divided into three categories - general, listing characteristics, and listing outcomes. General variables are the numbers of loans and listings. The category of listing characteristics contains variables that are included in the verified part of the listing such as the amount requested by the borrower and the number of delinquencies the borrower suffered from in the last seven years. The listing outcome category includes variables such as a listing's probability to be funded and variables summarizing the borrower's repayments in the first 18 payments in case it is funded. The following repayment variables are presented: An indicator whether a borrower paid each of the first 18 payments, an indicator whether the borrower paid the $18^{\text {th }}$ payment, the number of missing payments in the first 18 payments (censored from above at 4 ), and the probability of default. The summary statistics are calculated separately for each of the three defined groups of borrowers as well as for the full sample. The statistics that are presented for each variable are the mean, the standard deviation and the $10^{\text {th }}$ and $90^{\text {th }}$ percentiles of its distribution. 
Table 2: Summary Statistics - Borrower's Provided Information

\begin{tabular}{|c|c|c|c|c|}
\hline & Super Prime & Prime & Sub prime & Total \\
\hline \multicolumn{5}{|c|}{ Key Word Appears in the Listing's Title } \\
\hline Help & 0.047 & 0.068 & 0.103 & 0.090 \\
\hline Credit Card & 0.194 & 0.245 & 0.186 & 0.200 \\
\hline Debt & 0.112 & 0.144 & 0.159 & 0.151 \\
\hline Consolidate & 0.008 & 0.008 & 0.009 & 0.009 \\
\hline Start Business & 0.022 & 0.036 & 0.031 & 0.031 \\
\hline Real Estate & 0.013 & 0.020 & 0.030 & 0.026 \\
\hline Student & 0.001 & 0.002 & 0.002 & 0.002 \\
\hline School & 0.015 & 0.019 & 0.015 & 0.016 \\
\hline Tuition & 0.012 & 0.007 & 0.003 & 0.005 \\
\hline Medical & 0.016 & 0.016 & 0.020 & 0.019 \\
\hline Doctor & 0.002 & 0.004 & 0.010 & 0.008 \\
\hline Fresh & 0.004 & 0.005 & 0.006 & 0.006 \\
\hline Good Guy & 0.0002 & 0.0000 & 0.0001 & 0.0001 \\
\hline \multicolumn{5}{|l|}{ Loan Category } \\
\hline Debt Consolidation & 0.315 & 0.415 & 0.397 & 0.393 \\
\hline Home Improvement Loan & 0.063 & 0.043 & 0.026 & 0.033 \\
\hline Business Loan & 0.257 & 0.185 & 0.096 & 0.131 \\
\hline Personal Loan & 0.151 & 0.146 & 0.194 & 0.179 \\
\hline Student Loan & 0.031 & 0.026 & 0.032 & 0.031 \\
\hline Auto Loan & 0.024 & 0.018 & 0.022 & 0.021 \\
\hline Other & 0.085 & 0.063 & 0.075 & 0.073 \\
\hline \multicolumn{5}{|l|}{ Income } \\
\hline$\$ 1-24,999$ & 0.078 & 0.103 & 0.165 & 0.143 \\
\hline$\$ 25,000-49,999$ & 0.265 & 0.327 & 0.440 & 0.398 \\
\hline$\$ 50,000-74,999$ & 0.223 & 0.246 & 0.217 & 0.224 \\
\hline$\$ 75,000-99,999$ & 0.132 & 0.116 & 0.069 & 0.085 \\
\hline$\$ 100,000+$ & 0.168 & 0.111 & 0.043 & 0.070 \\
\hline \multicolumn{5}{|c|}{ Employment } \\
\hline Full Time & 0.743 & 0.802 & 0.840 & 0.822 \\
\hline Not Employed & 0.020 & 0.019 & 0.020 & 0.020 \\
\hline Part Time & 0.030 & 0.030 & 0.038 & 0.035 \\
\hline Retired & 0.033 & 0.033 & 0.030 & 0.031 \\
\hline Self-Employed & 0.173 & 0.117 & 0.072 & 0.092 \\
\hline
\end{tabular}




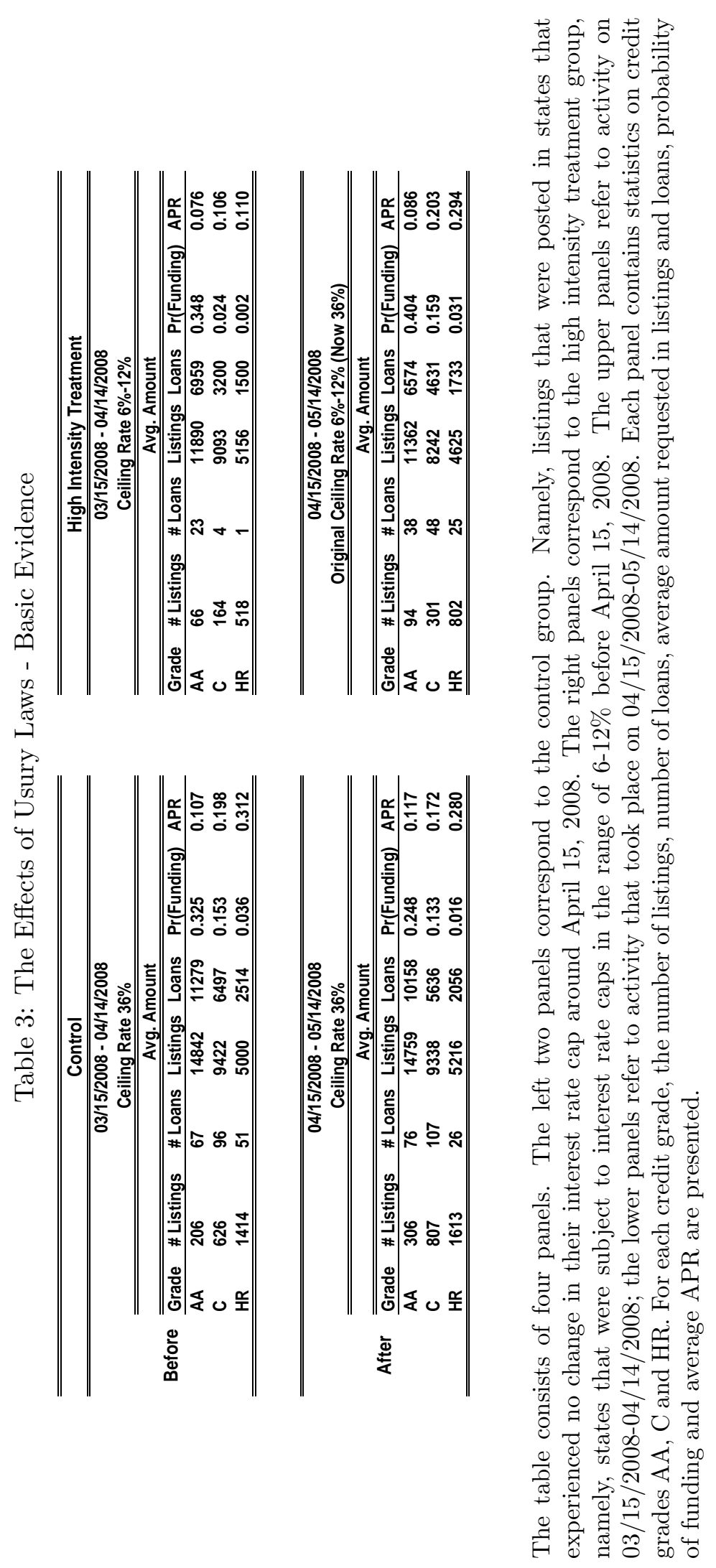




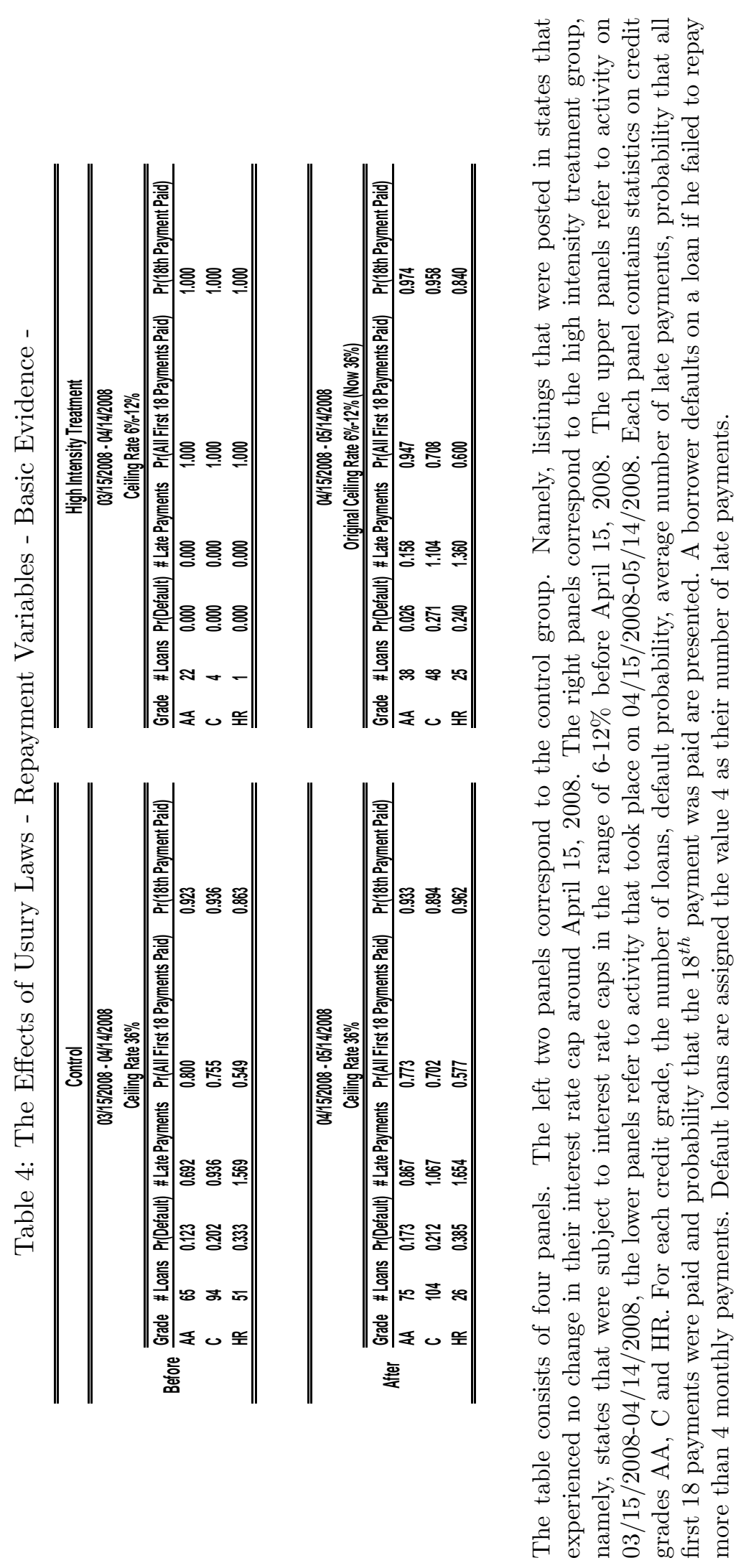




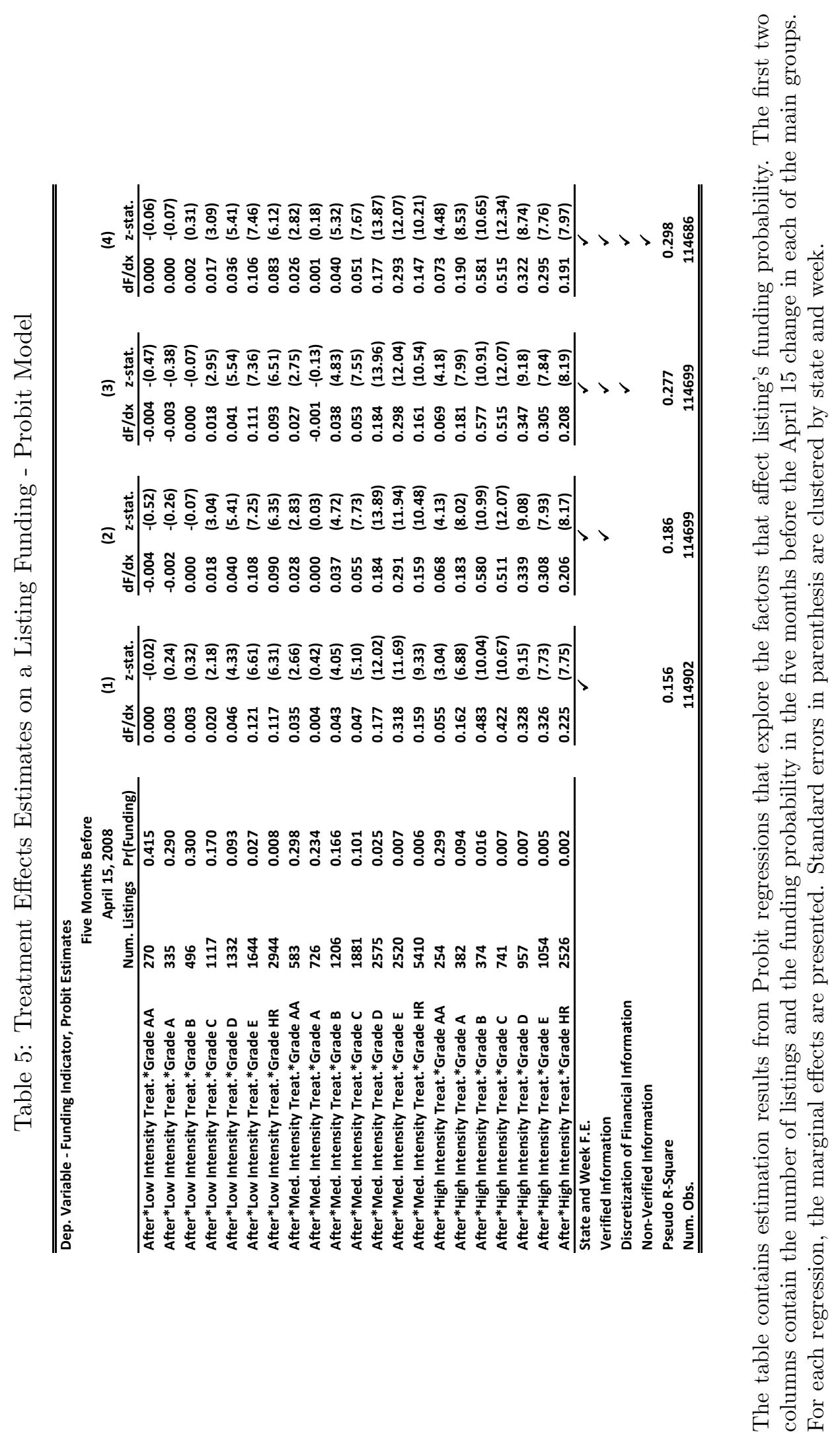




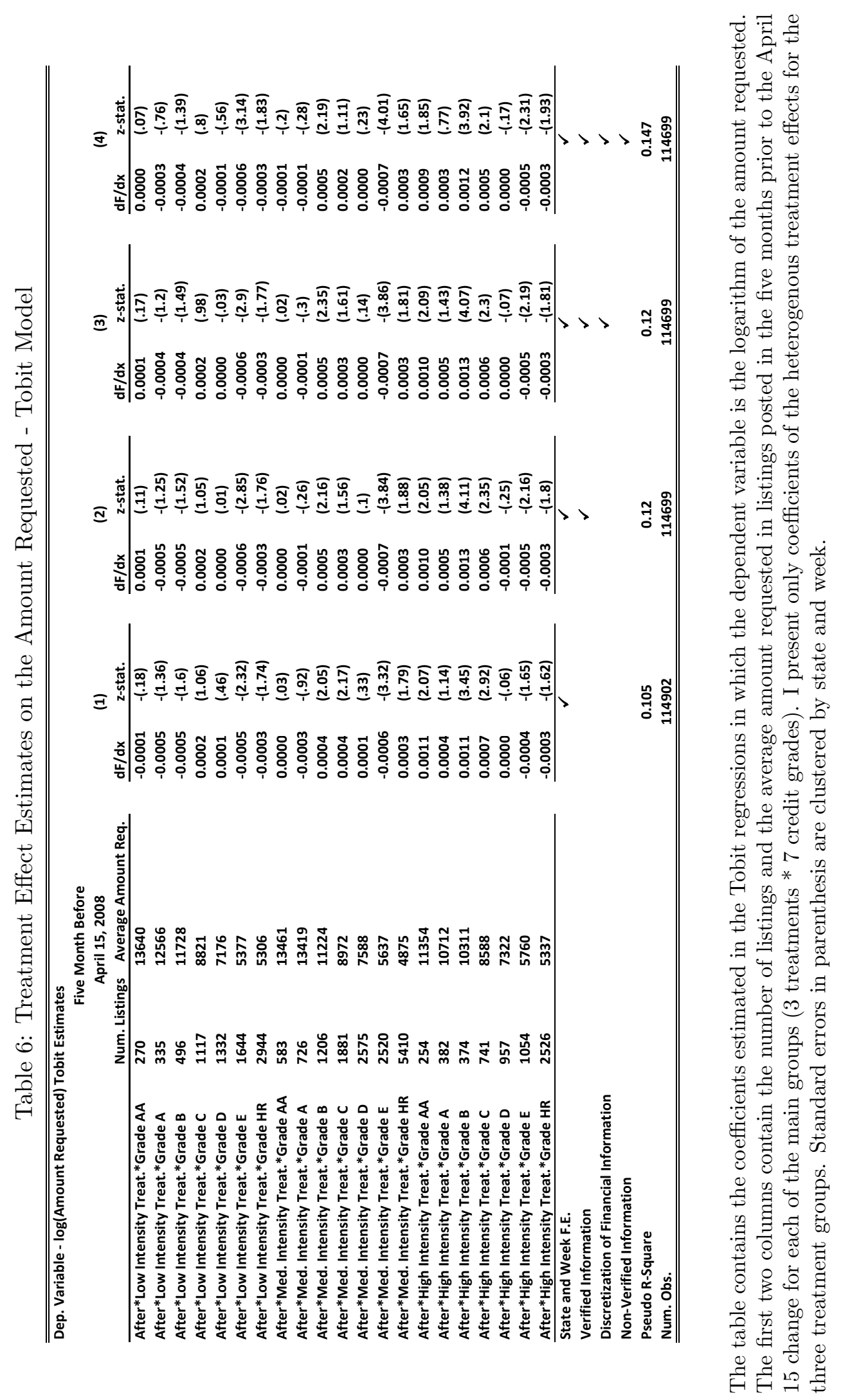




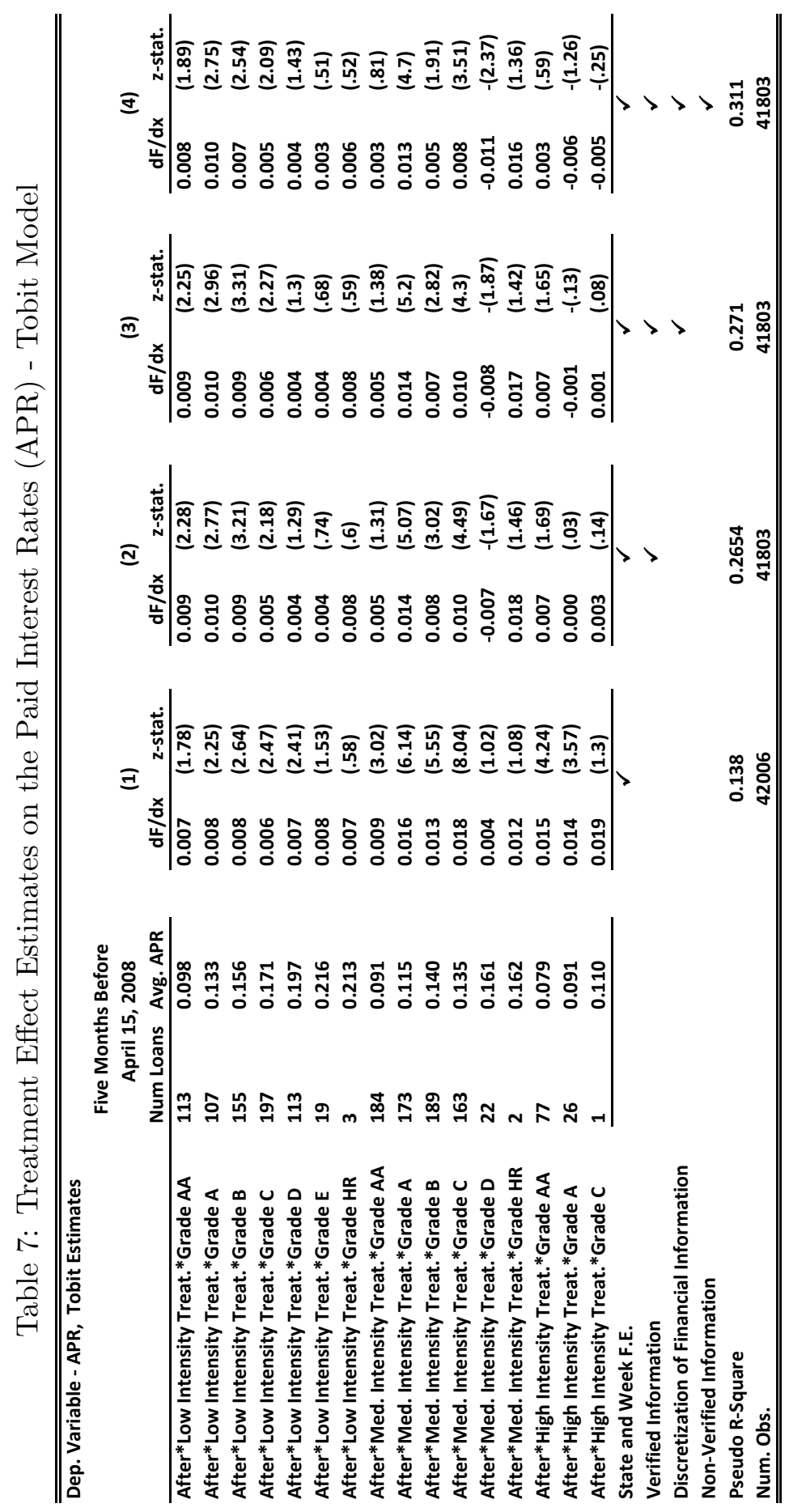

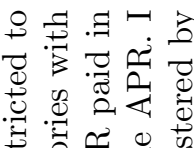

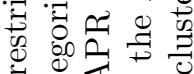

.

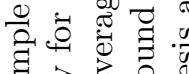

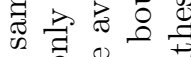

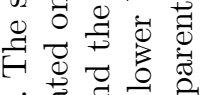

๙

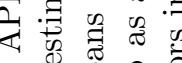

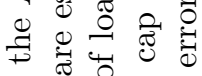

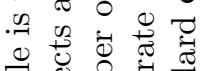

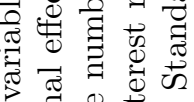

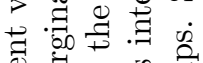

ฮี

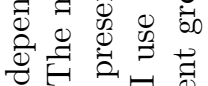

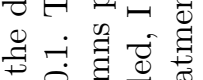

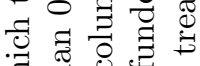

$\exists \quad \begin{aligned} & 0 \\ & 1\end{aligned}$

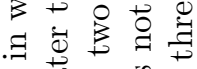

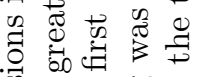

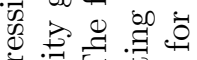

焉:

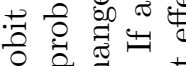

정

엽 곡

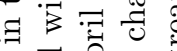

웡 दे

总录昰。

원

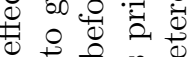

๘

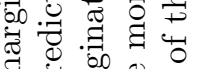

घ

䨌

疍

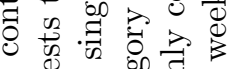

윰 它

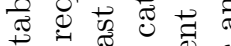

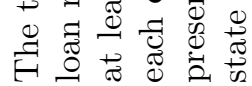




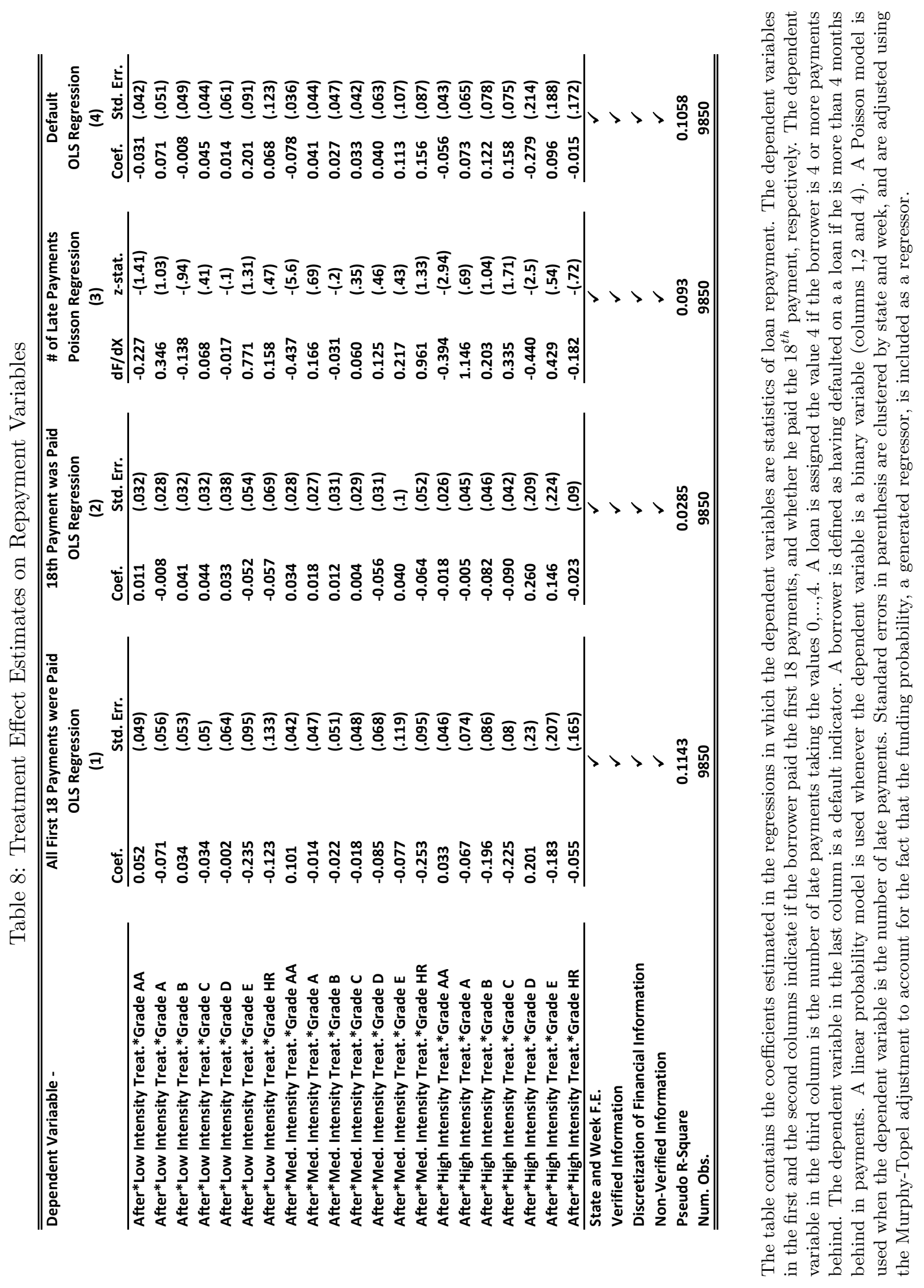


Table 9: Prevalence of Repost Episodes

\begin{tabular}{llllllll}
\hline \hline & \multicolumn{8}{c}{ Maximum Number of Hours } \\
& \multicolumn{1}{c}{ Between a Listing Expiration/Withdrawn and Repost by the Same Borrower } \\
\hline & 12 & 24 & 48 & 72 & 96 & 120 & 240 \\
\hline \# Borrowers & 3,832 & 5,244 & 6,985 & 8,216 & 9,475 & 10,388 & 17,489 \\
\# Loan requests & 9,157 & 12,900 & 17,737 & 21,247 & 25,317 & 28,229 & 52,654 \\
\hline \hline
\end{tabular}

The table contains the numbers of borrowers and listings for various definitions of listing repost episode. A borrower's repost episode is defined as a sequence of listings posted by the same borrower in which any listing posted within a short time after the previous listing was expired or withdrawn. The various definitions are distinguished by the upper limit of what short time is. For example, the last column should be read as follows: 17,489 borrowers has at least one event in which they repost a listing less than 10 days after their previous one was expired or withdrawn. 52,654 listings were posted in such repost episodes. 
Figure 1: The Number of Listings and Loans Over Time
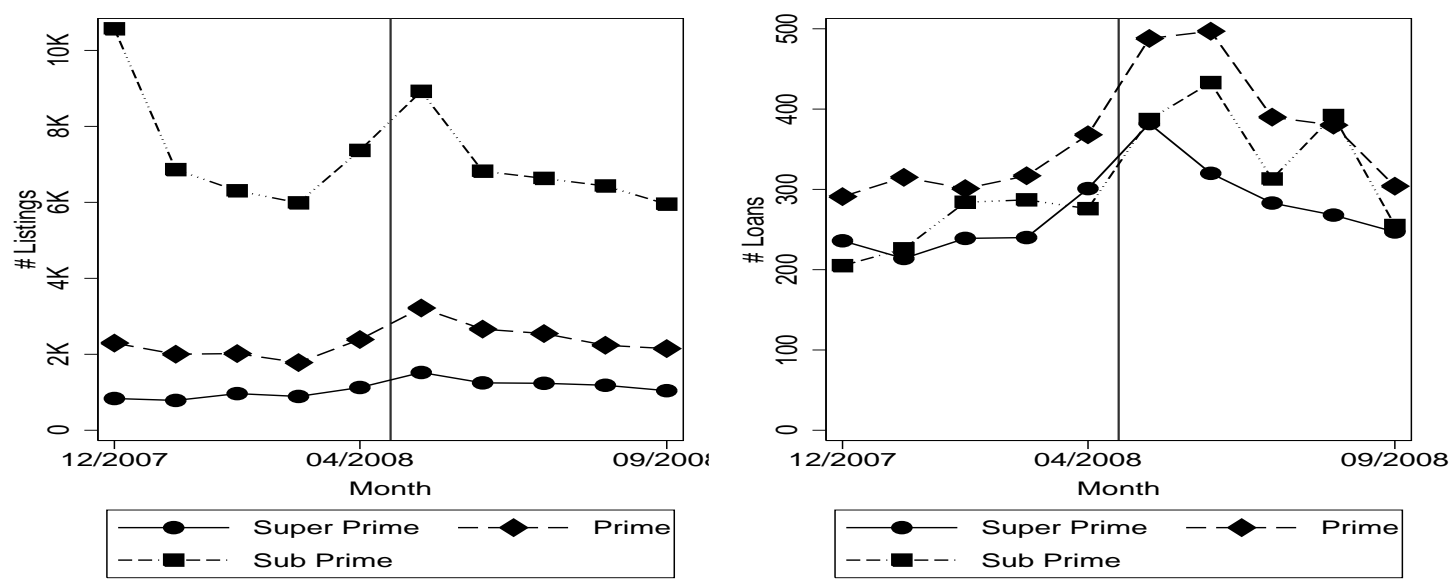

The figure graphs the monthly number of listing and loans. The left figure corresponds to the number of listings, and the right to the number loans. Within each graph, borrowers are clustered by their credit score. I define borrowers with credit scores above 720 as super prime borrowers. Borrowers with credit scores in the range 640-719 as prime borrowers and borrowers with credit scores below 640 but above 520 are defined as sub prime borrowers. The vertical line marks the April 15 change in which the maximum interest rate allowed for a borrower to pay was set at $36 \%$ in all states. Since the change occurred in the middle of a month I relabel time accordingly. For example, the activity that is marked on April 2008 corresponds to the time period that starts on March 15, 2008 and ends on April 14, 2008. In addition, I omit the number of listings and loans from 10/30/2007-11/14/2007 because this time period includes less than a month-long of data. 
Figure 2: Probability of Funding Over Time

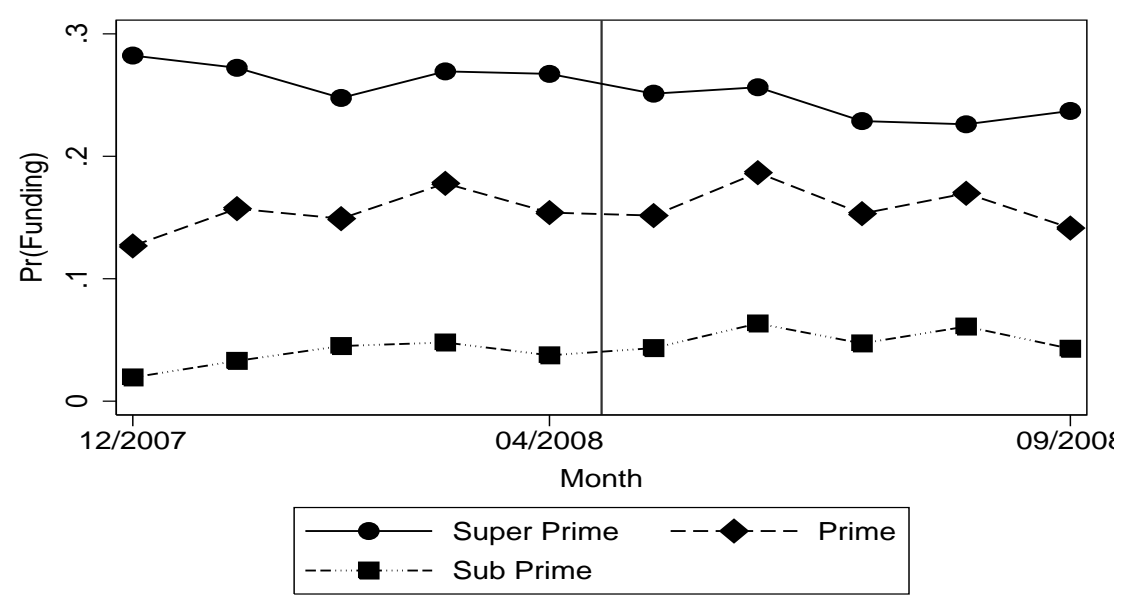

The figure graphs the change over time in the funding probability of listings. Listings are clustered into groups based on their credit score. Borrowers are clustered by their credit score. I define borrowers with credit scores above 720 as super prime borrowers. Borrowers with credit scores in the range 640-719 as prime borrowers and borrowers with credit scores below 640 but above 520 are defined as sub prime borrowers. The vertical line marks the April 15 change in which the maximum interest rate allowed for a borrower to pay was set at $36 \%$ in all the states. Since this change occurred in the middle of a month I relabel time accordingly. For example, the activity that is marked on April 2008 corresponds to the time period that starts on March 15, 2008 and ends on April 14, 2008. In addition, I omit the number of listings and loans from 10/30/2007-11/14/2007 because this time period includes less than a month long of data. 
Figure 3: Average Amount Requested Over Time
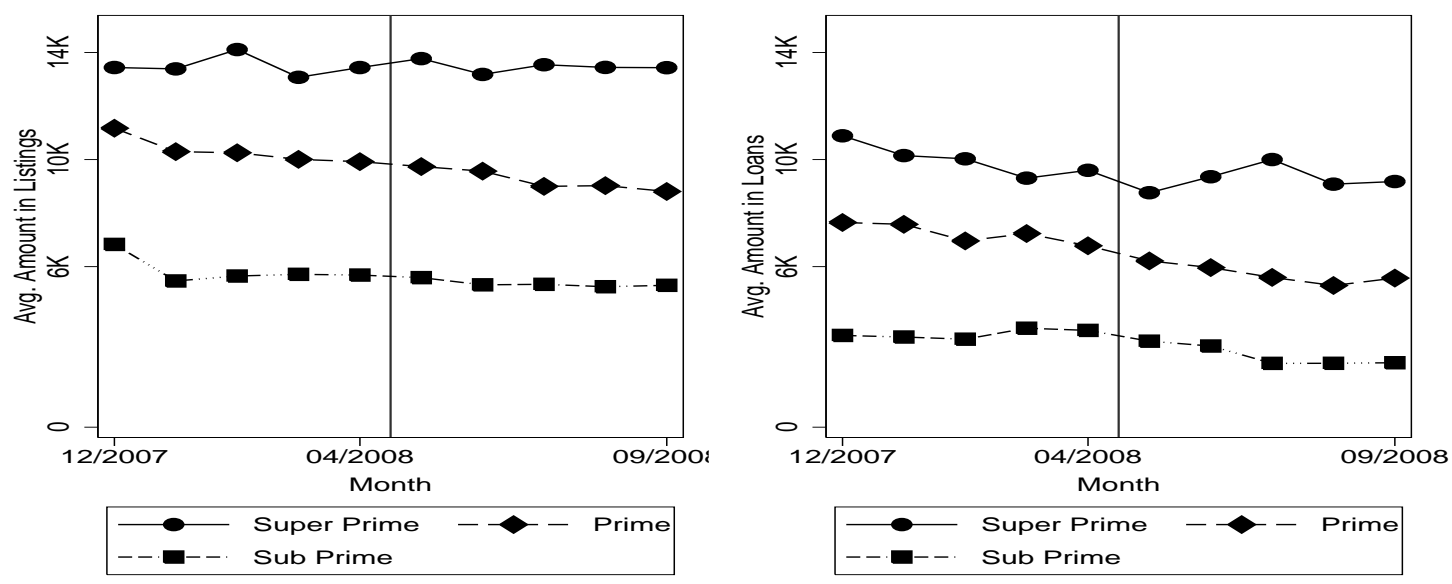

The figure contains the monthly average amount requested by borrowers. The left graph presents the amount requested in listings, while the right corresponds to loans. Within each graph, borrowers are clustered by their credit score. I define borrowers with credit scores above 720 as super prime borrowers. Borrowers with credit scores in the range of 640-719 are defined as prime borrowers and borrowers with credit scores below 640 but above 520 are defined as sub prime borrowers. The vertical line marks the April 15 change in which the maximum interest rate allowed for a borrower to pay was set at $36 \%$ in all the states. Since the change occurred in the middle of a month I relabel time accordingly. For example, the activity that is marked on April 2008 corresponds to the time period that starts on March 15, 2008 and ends on April 14, 2008. In addition, I omit the number of listings and loans from $10 / 30 / 2007-11 / 14 / 2007$ because this time period includes less than a month long of data. 
Figure 4: Average Interest Rate Over Time

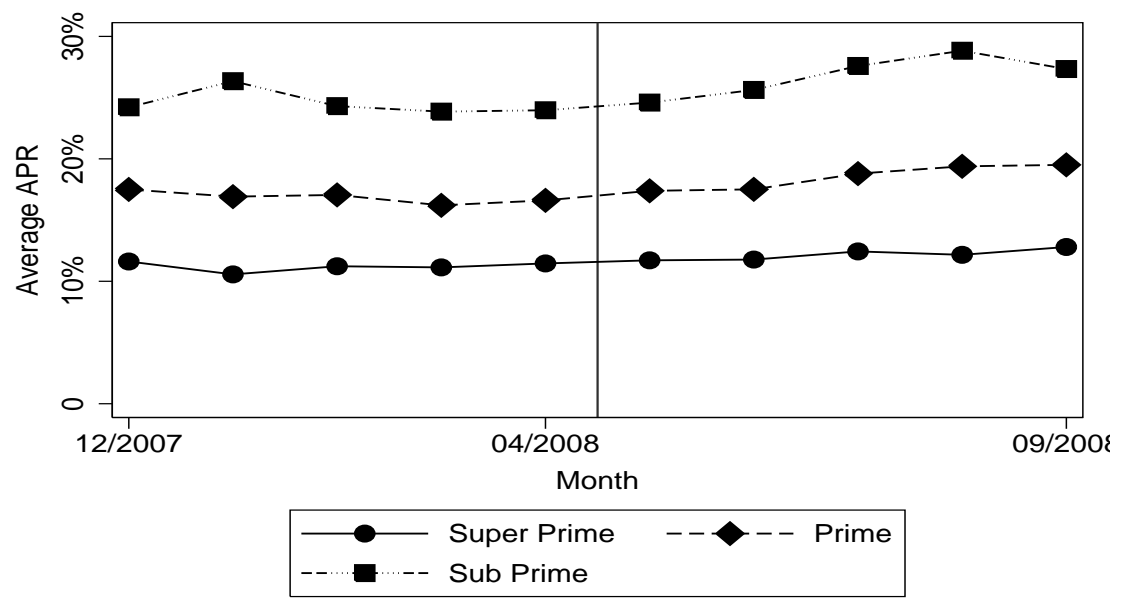

The figure contains the monthly average APR paid by borrowers. Borrowers are clustered by their credit score. I define borrowers with credit scores above 720 as super prime borrowers. Borrowers with credit scores in the range 640-719 as prime borrowers and borrowers with credit scores below 640 but above 520 are defined as sub prime borrowers. The vertical line marks the April 15 change in which the maximum interest rate allowed for a borrower to pay was set at $36 \%$ in all states. Since the change occurred in the middle of a month I relabel time accordingly. For example, the activity that is marked on April 2008 corresponds to the time period that starts on March 15, 2008 and ends on April 14, 2008. In addition, I omit the number of listings and loans from 10/30/2007-11/14/2007 because this time period includes less than a month long of data. 


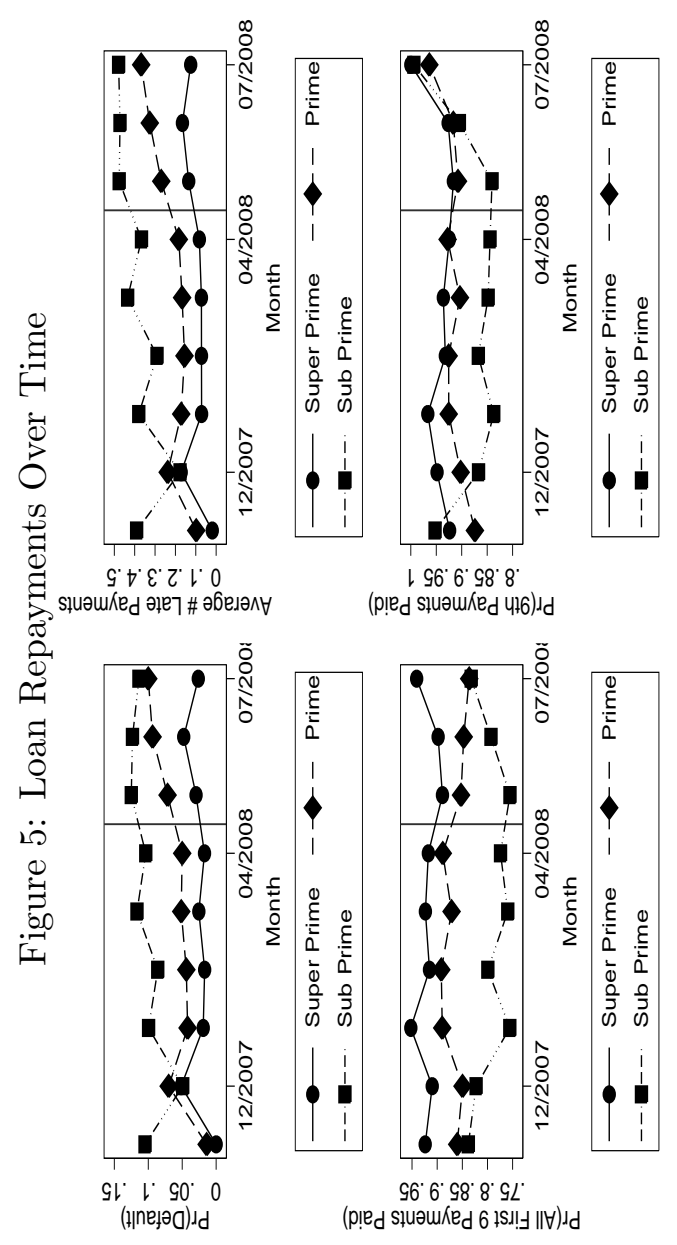

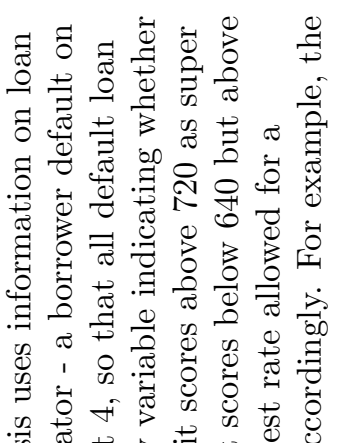

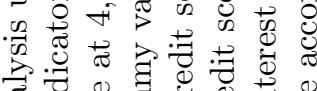

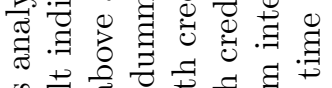

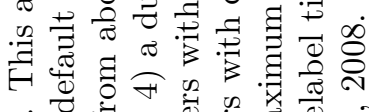

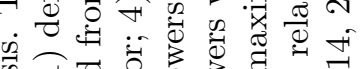

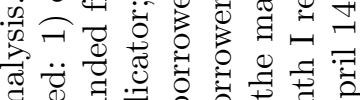

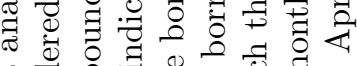

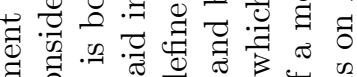

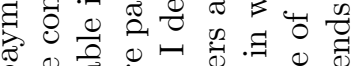

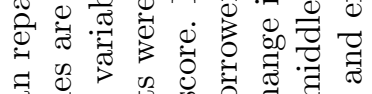

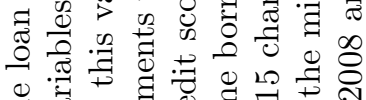

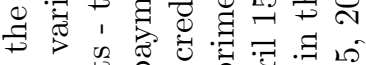

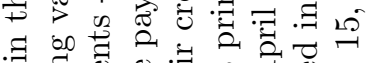

च औ

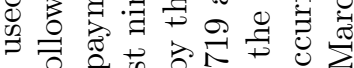

क

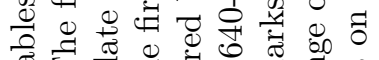

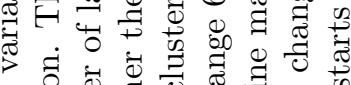

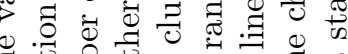

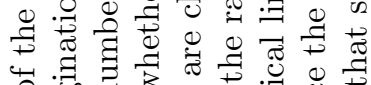

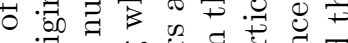

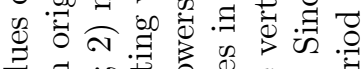

ॠี

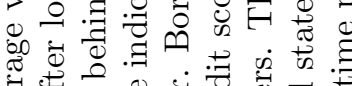

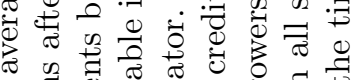
\%

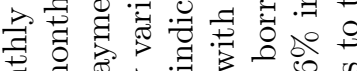

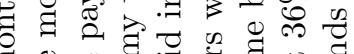

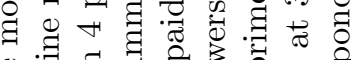

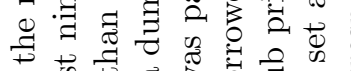

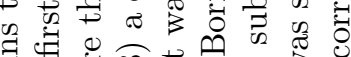

ส

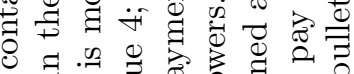

ซ

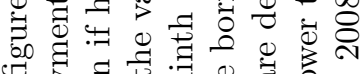

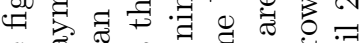

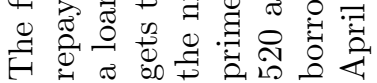


Figure 6: Fraction of Listings Posted Under Various Interest Rate Caps - Before 04/15/2008

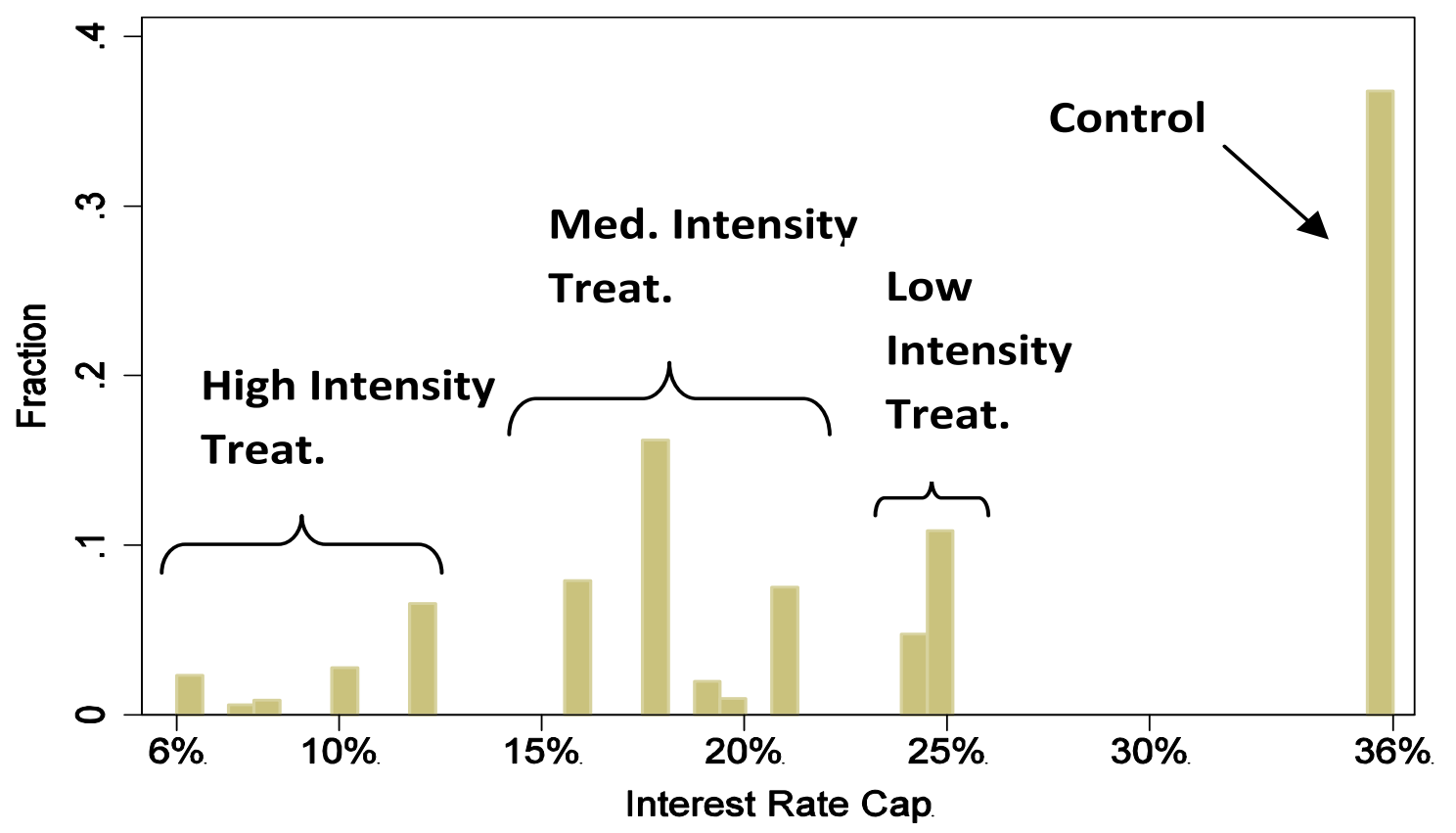

The figure contains the distribution of interest rate caps in listings posted before April 15, 2008 and maps interest rate caps into the different treatment and control groups. 


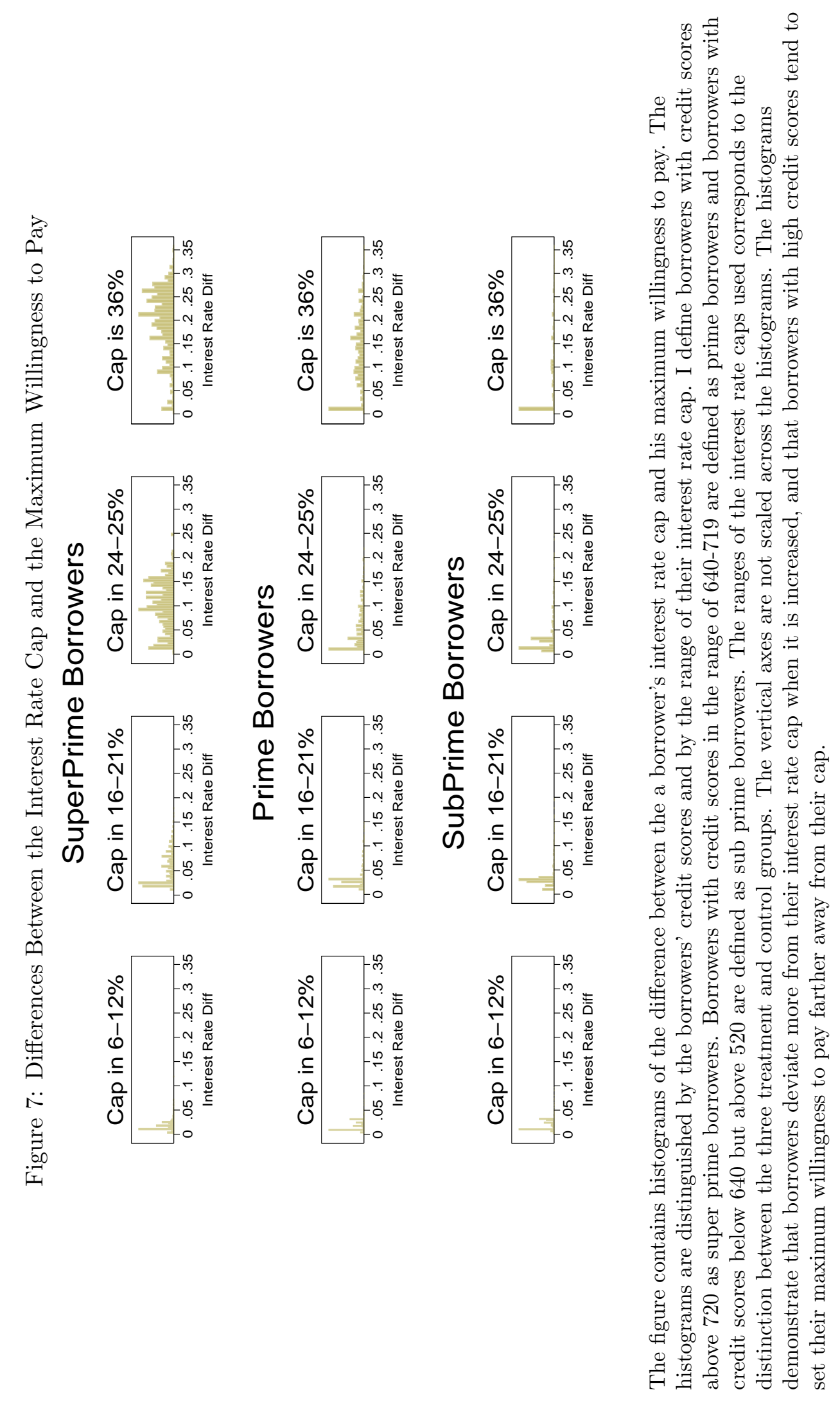


Figure 8: Changes in the Funding Probability
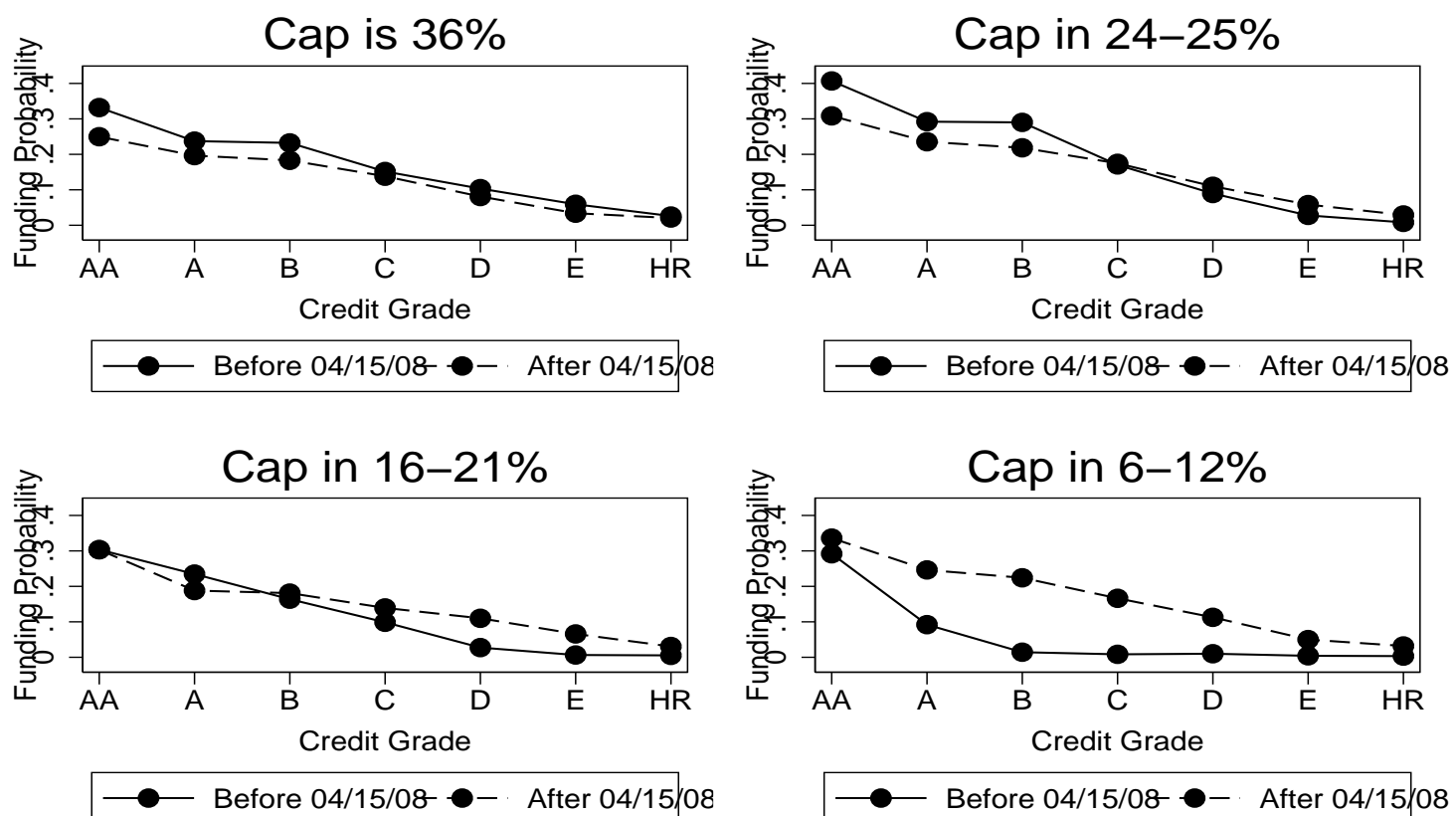

The figure presents the funding probability of listings such that it is analogous to the empirical strategy implemented. Listings are clustered by posting time (before vs. after April 15, 2008), association with a treatment or control group, and a credit grade. The upper left figure corresponds to the control group. The vertical difference between the before and after lines demonstrates the time trend in the funding probability. The vertical differences in the other figures that are in excess of the upper left figure time trend correspond to the treatment effects. While these treatment effects do not account for the selection of listings into the sample, they are qualitatively the same as those obtained once selection is accounted for. 
Figure 9: Treatment Effect on the Funding Probability
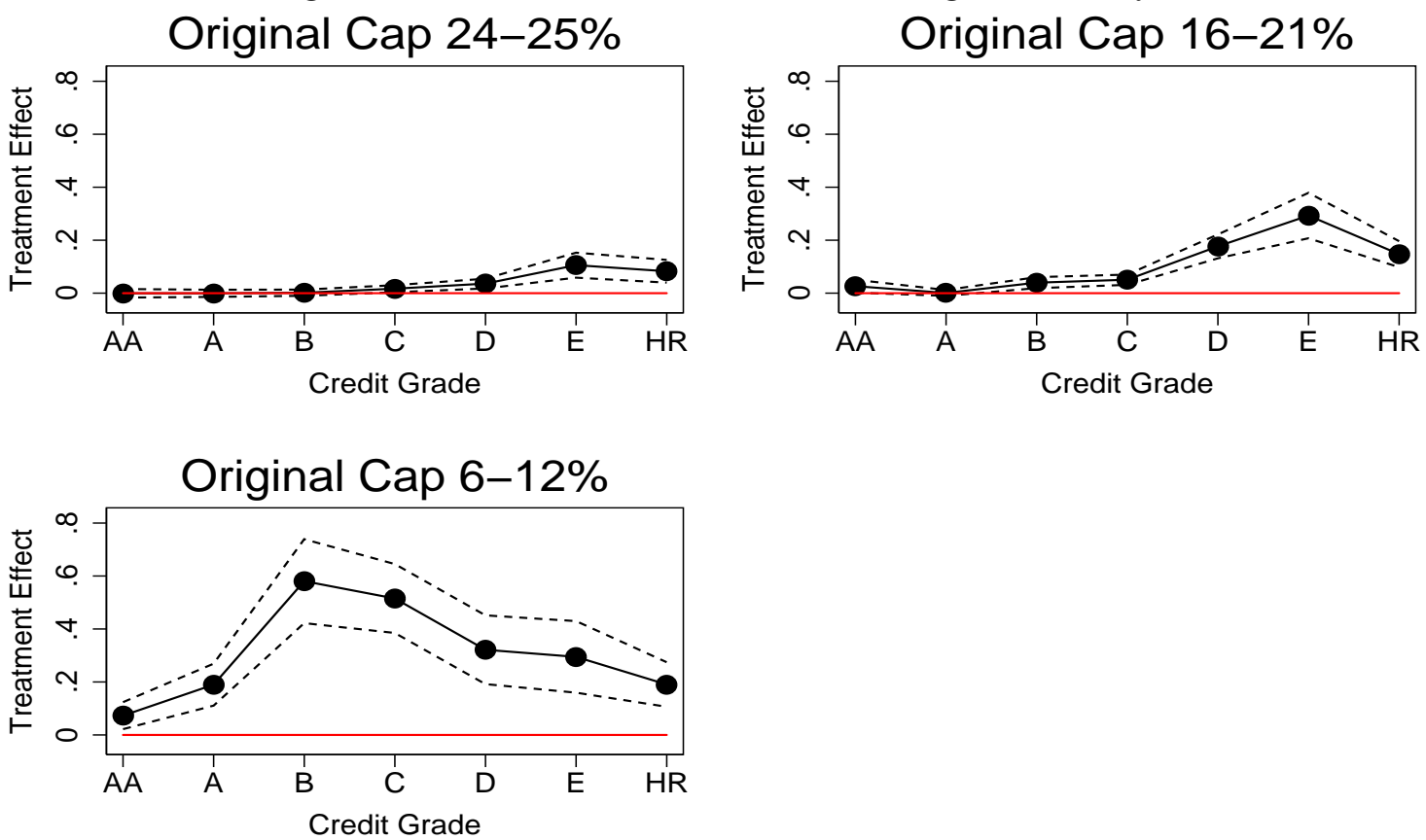

The figure contains a graphical representation of the treatment effect on the funding probability. The point estimates and the $95 \%$ confidence intervals of the treatment effect for any treatment group credit grade combination based on column 4 of Table 5 are included in the graph.

Figure 10: Average APR in Control Group Before the April 15 Change

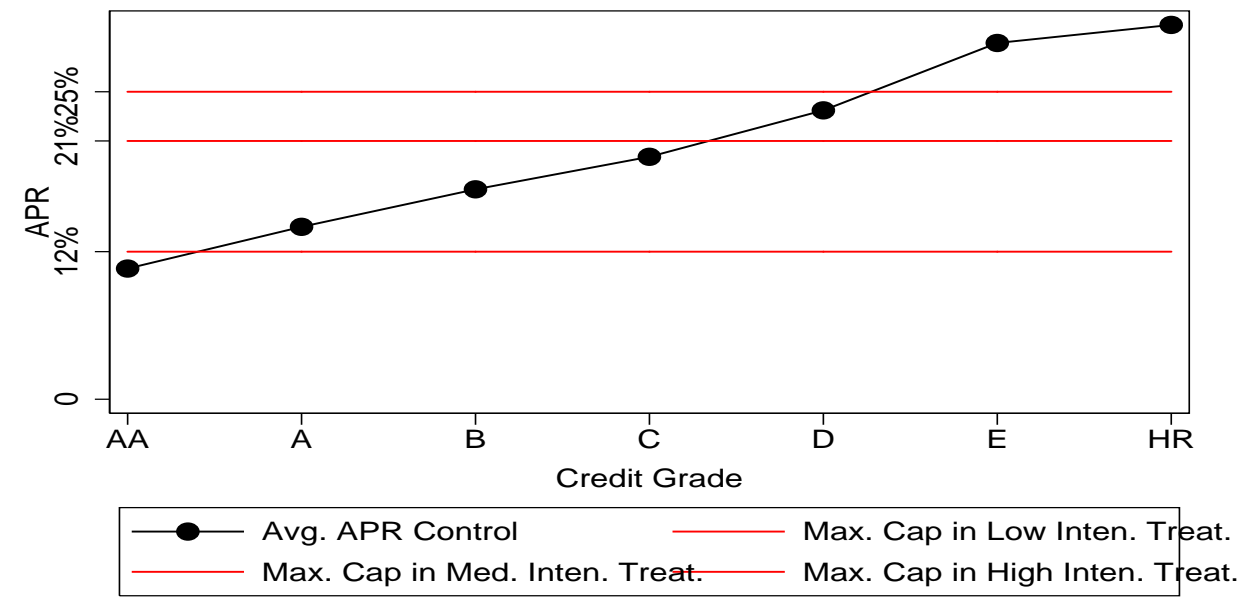

The figure contains the average APR observed in the control group before the change. The three horizontal lines in $12 \%, 21 \%$ and $25 \%$ correspond to the highest interest rate allowed in the high, medium and low intensity treatment groups, respectively. 
Figure 11: Treatment Effect on the Amount Requested
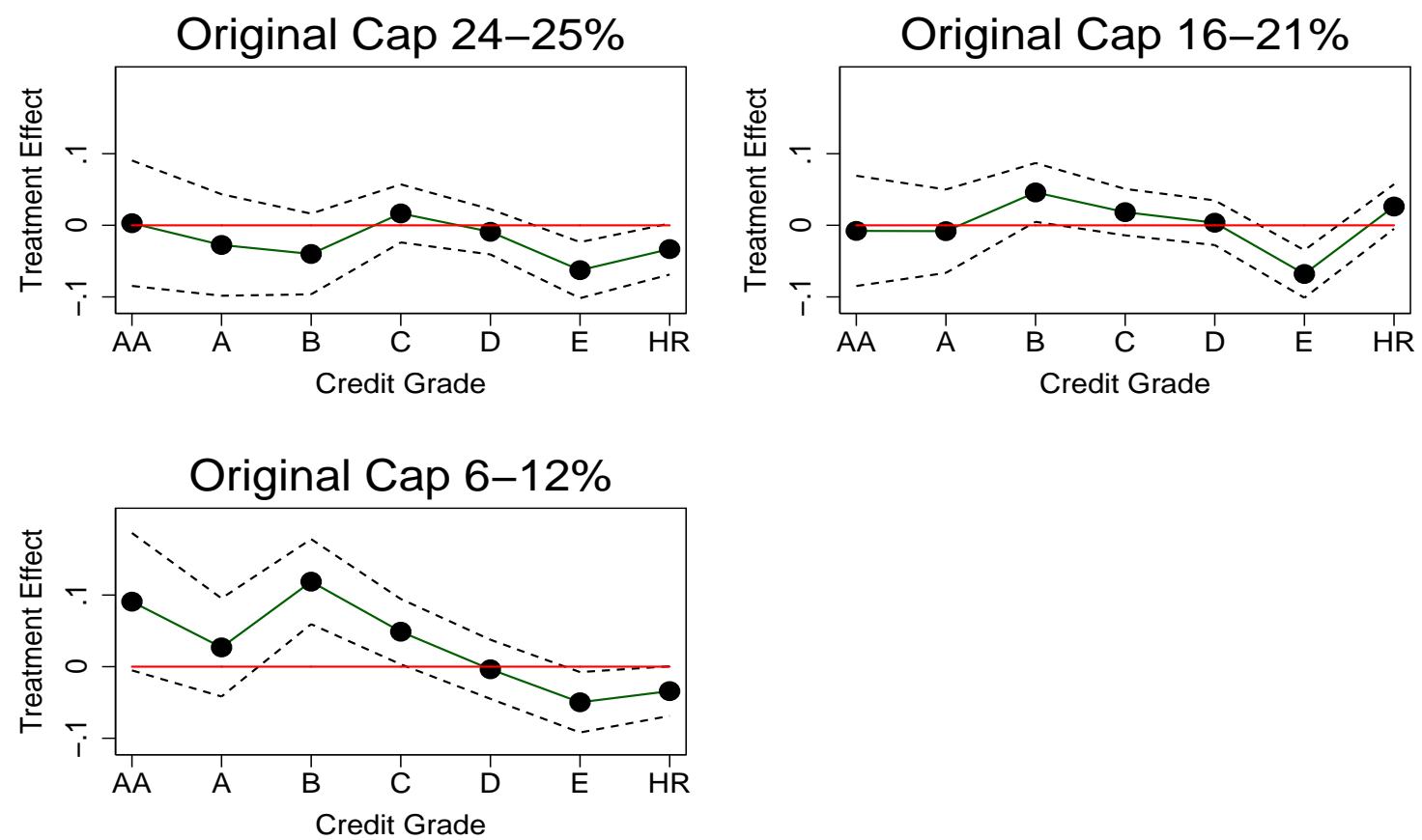

The figure contains a graphical representation of the treatment effect on the amount requested. The point estimates and the $95 \%$ confidence intervals of the treatment effect for any treatment group credit grade combination based on column 4 of Table 6 are included in the graph. 
Figure 12: Treatment Effect on the APR - Threshold at Funding Probability of 0.1

Original Cap 24-25\%

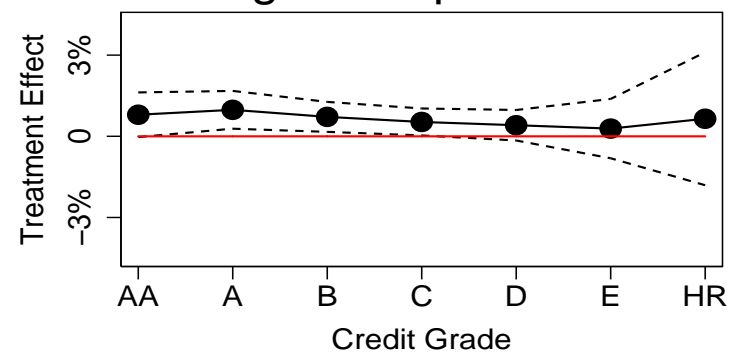

Original Cap $6-12 \%$

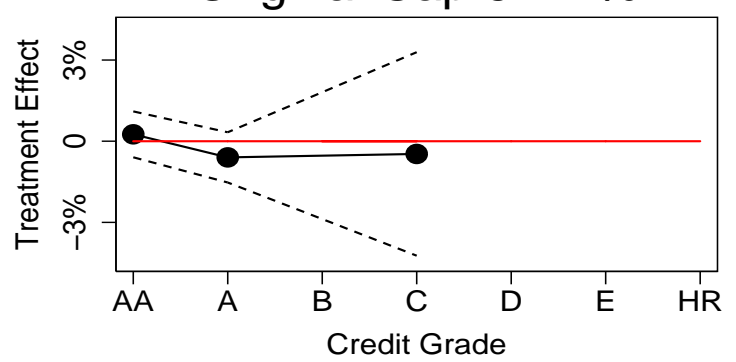

Original Cap $16-21 \%$

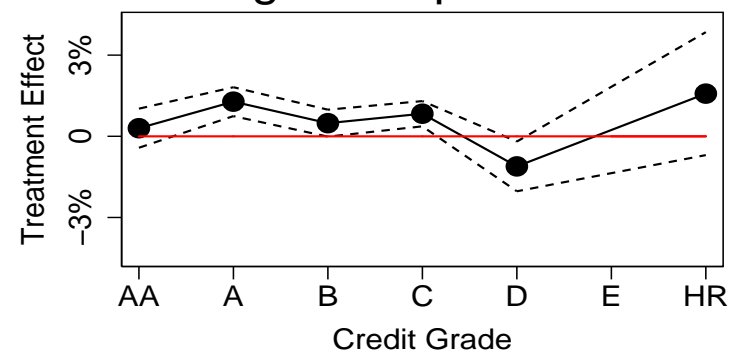

The figure contains a graphical representation of the treatment effect on the APR. The point estimates of the marginal effect and the 95\% confidence interval are presented for combinations of treatment group credit grade. Only categories with at least a single loan originated before April 15, 2008 whose predicted funding probability is greater than 0.1 are included. The sample used for the estimation includes loan requests with a predicted funding probability greater than 0.1. The graph is based on column 4 of Table 7. 
Figure 13: Treatment Effect on the Probability that the First 18 Payments Were Paid
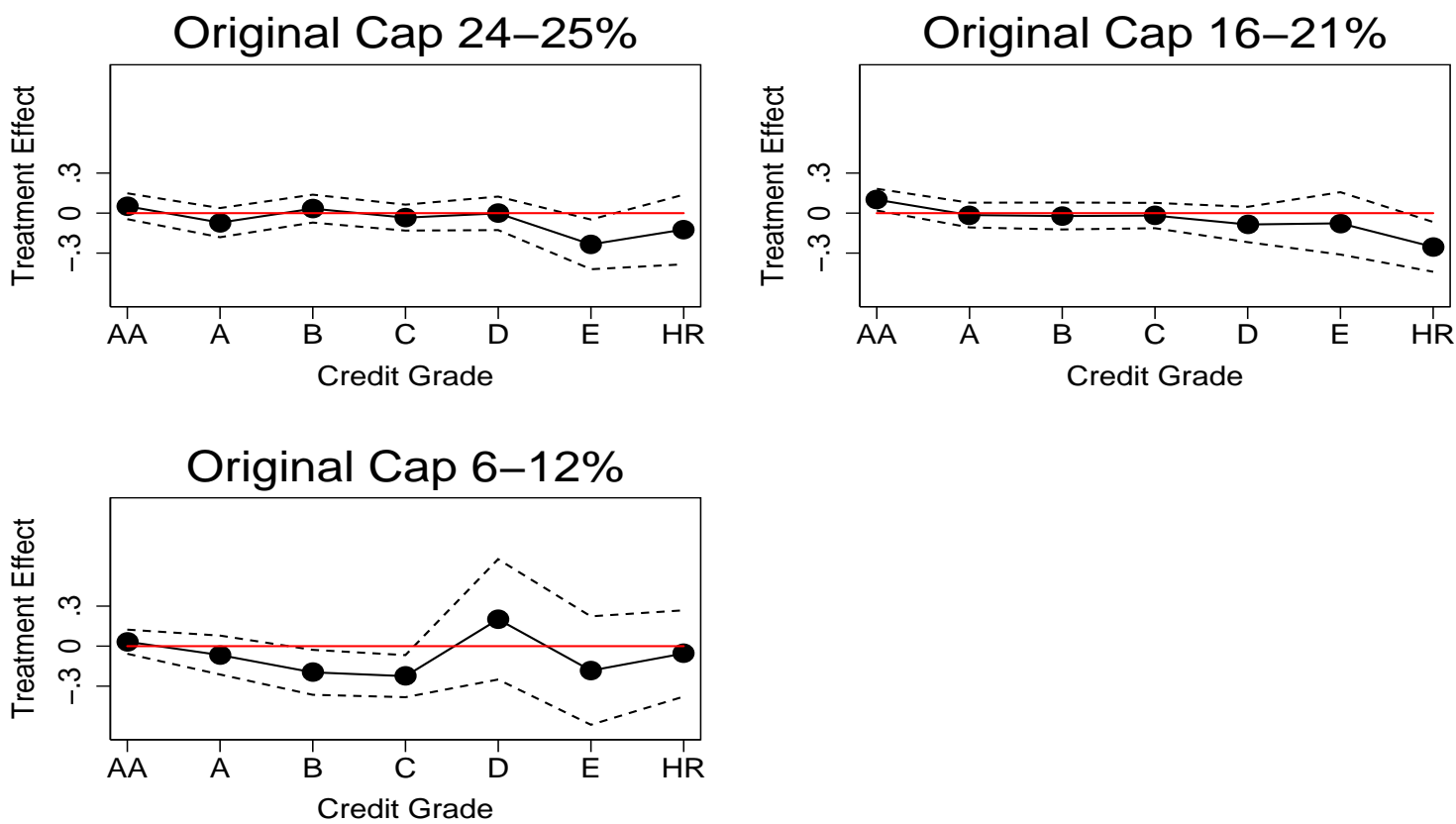

The figure contains a graphical representation of the treatment effects on the probability that a borrower repays the first 18 payments. The point estimates and the $95 \%$ confidence intervals of the treatment effect each category based on column 1 of Table 8 are included in the graph. 
Figure 14: Treatment Effect on the Probability that the Last $\left(18^{\text {th }}\right)$ Payment was Repaid
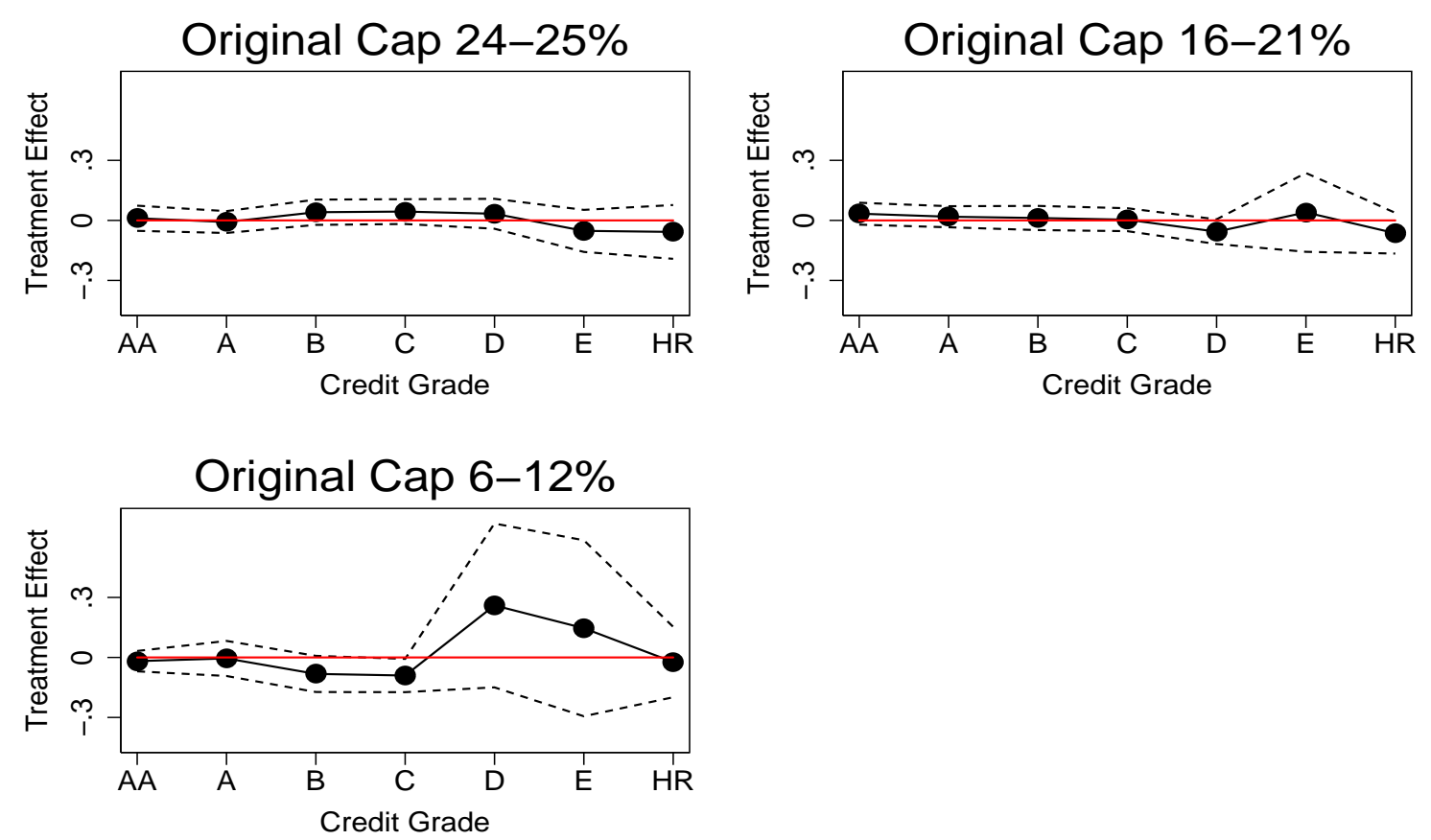

The figure contains a graphical representation of the treatment effect on the probability that a borrower repaid the last (i.e., the $18^{\text {th }}$ ) observed payment. The point estimates and the $95 \%$ confidence intervals of the treatment effects for each category based on column 2 of Table 8 are included. 
Figure 15: Treatment Effect on the Number of Late Payments
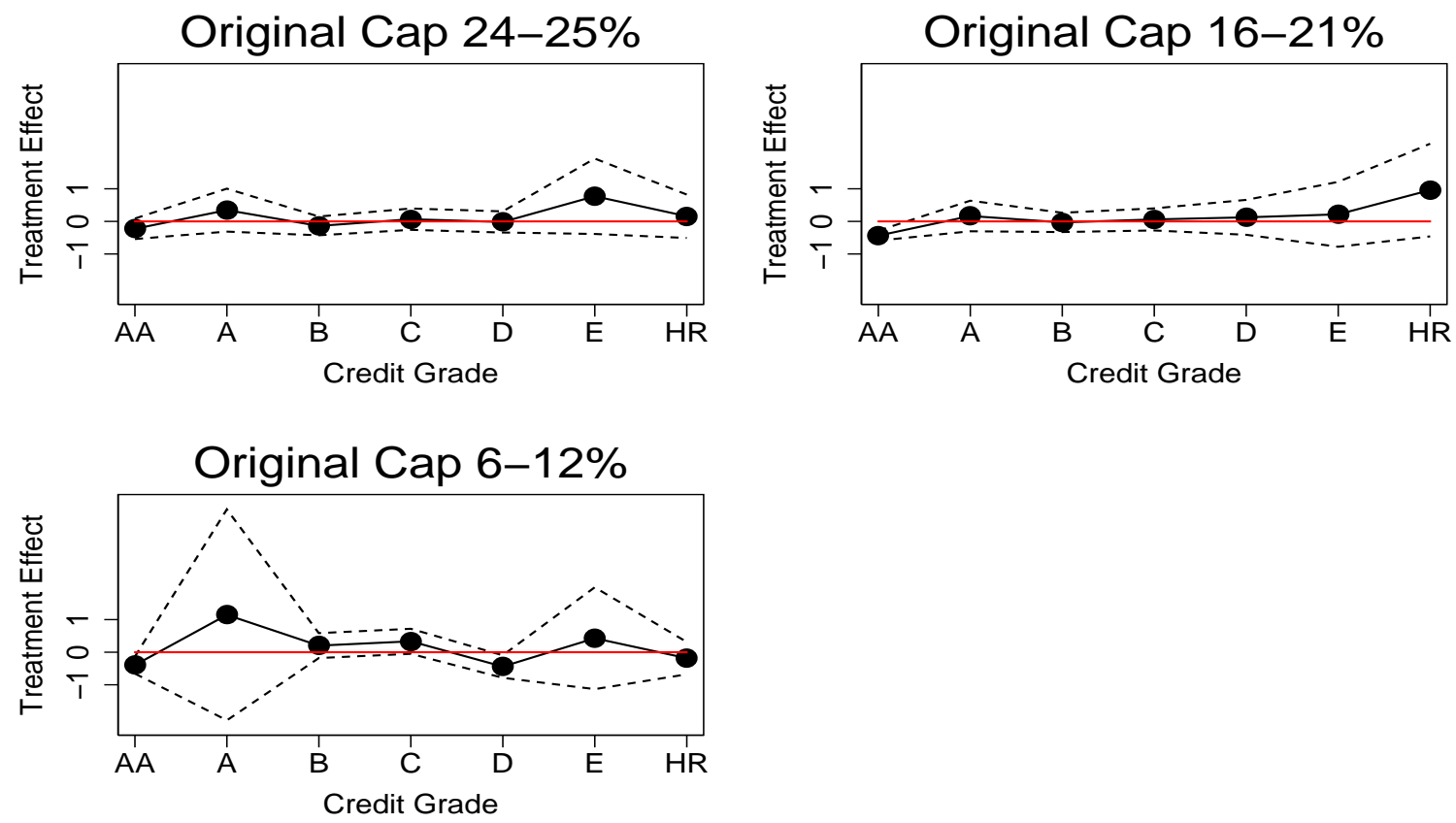

The figure contains a graphical representation of the treatment effect on the number of late payments in the first 18 payments. Any default loan is assigned the value 4 as its number of late payments. The point estimates and the $95 \%$ confidence intervals of the treatment effect for each category based on column 3 of Table 8 are included. 
Figure 16: Treatment Effect on the Default Probability
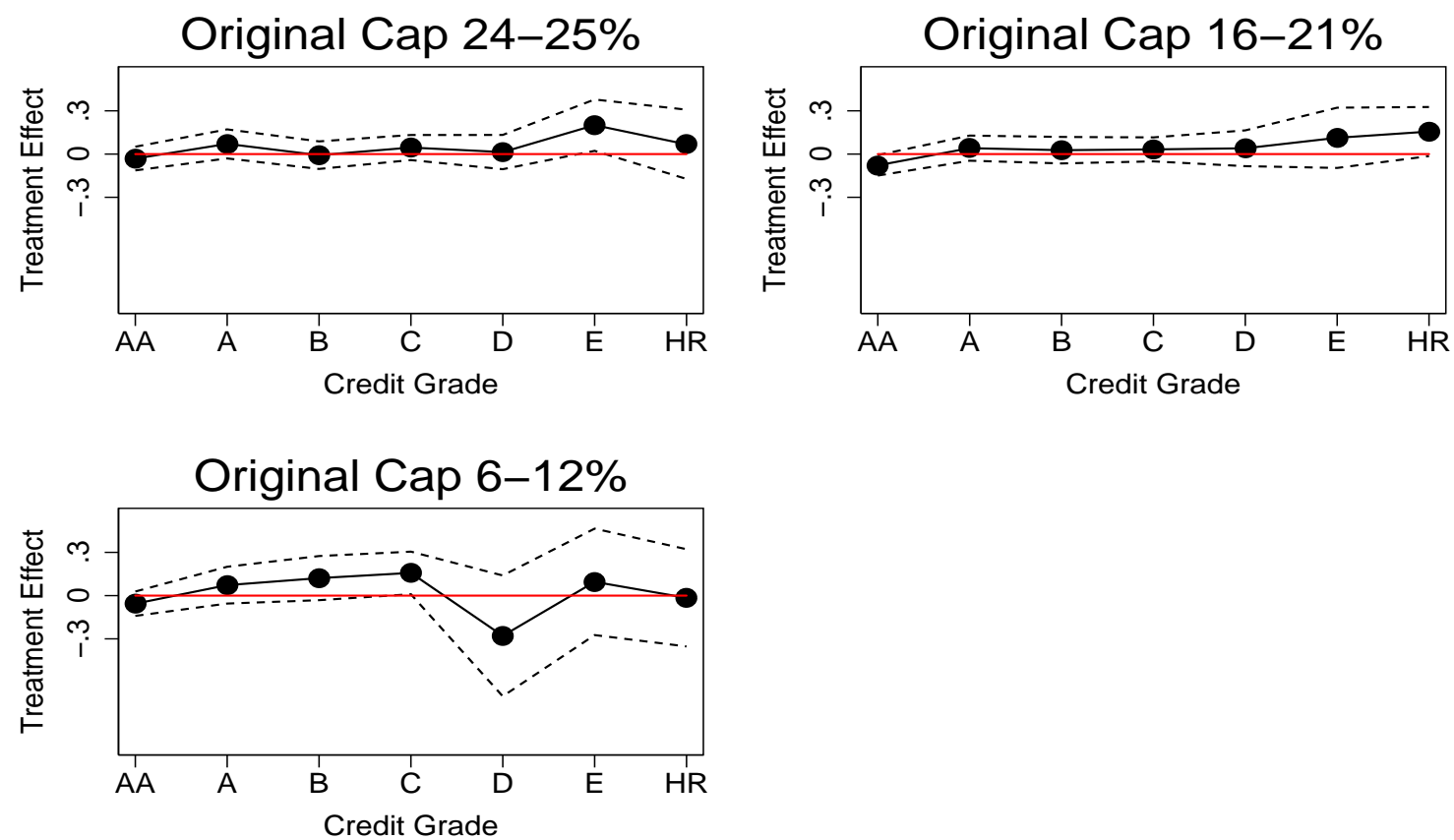

The figure contains a graphical representation of the treatment effect on the probability of default. A borrower defaults on a loan if he is more than 4 payments behind. The point estimates and the $95 \%$ confidence intervals of the treatment effects for each category based on column 4 of Table 8 are included. 
Figure 17: Treatment Effect on the Funding Probability - Full vs. Restricted Sample

Baseline Specification
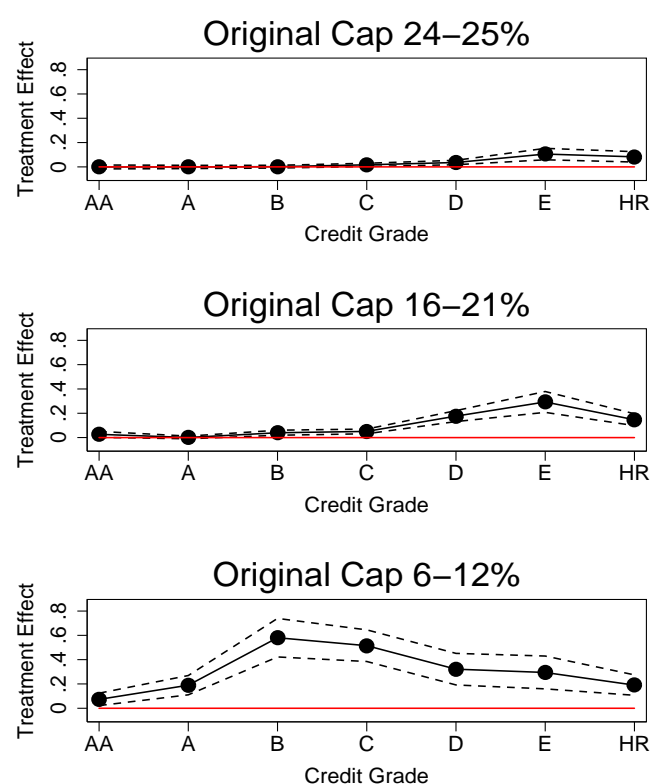

Narrow Time Window
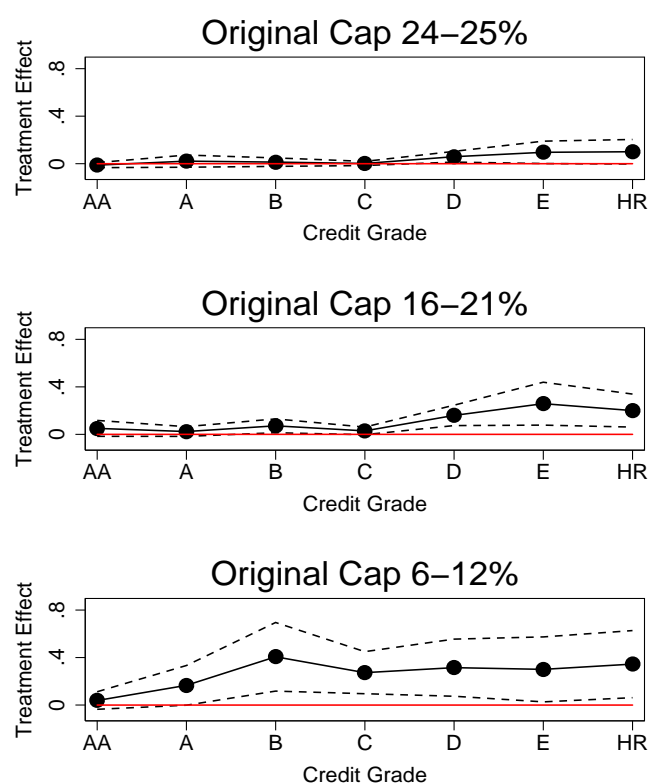

The figure contains a graphical representation of the treatment effect on the funding probability. Each column contains the point estimates and the $95 \%$ confidence interval. The left column is based on the full sample. The second column is based on a restricted sample that includes observations from one month before and one month after April 15, 2008. 